$\mathbb{N} \mathbf{K}$ IT

Karlsruhe Institute of Technology

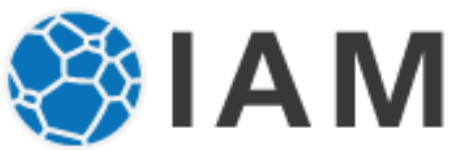

Institute for Applied Materials

\title{
Deviations from the parabolic kinetics during oxidation of zirconium alloys
}

Martin Steinbrück, Mirco Große

Karlsruhe Institute of Technology, Institute for Applied Materials, Germany

17th International Symposium on Zirconium in the Nuclear Industry, 03.-07.02.2013, Hyderabad, India

Institute for Applied Materials IAM-AWP \& Program NUKLEAR
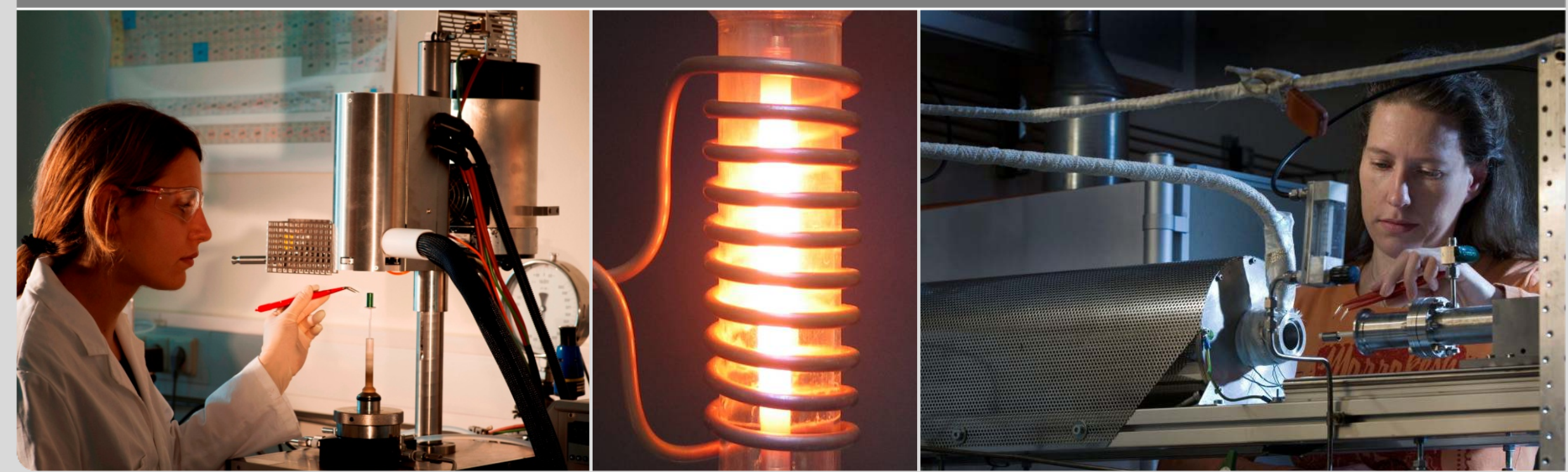

KIT - University of the State of Baden-Wuerttemberg and 


\section{Motivation}

- Oxidation of zirconium alloy claddings during severe accidents causes degradation of cladding and loss of barrier effect as well as production of hydrogen and heat

- Oxidation kinetics and corresponding hydrogen source term have to be known for appropriate accident management measures

- At KIT extensive investigations on oxidation of zirconium alloys in various atmospheres have been performed in the framework of the QUENCH program including integral bundle tests and smallscale separate-effects experiments

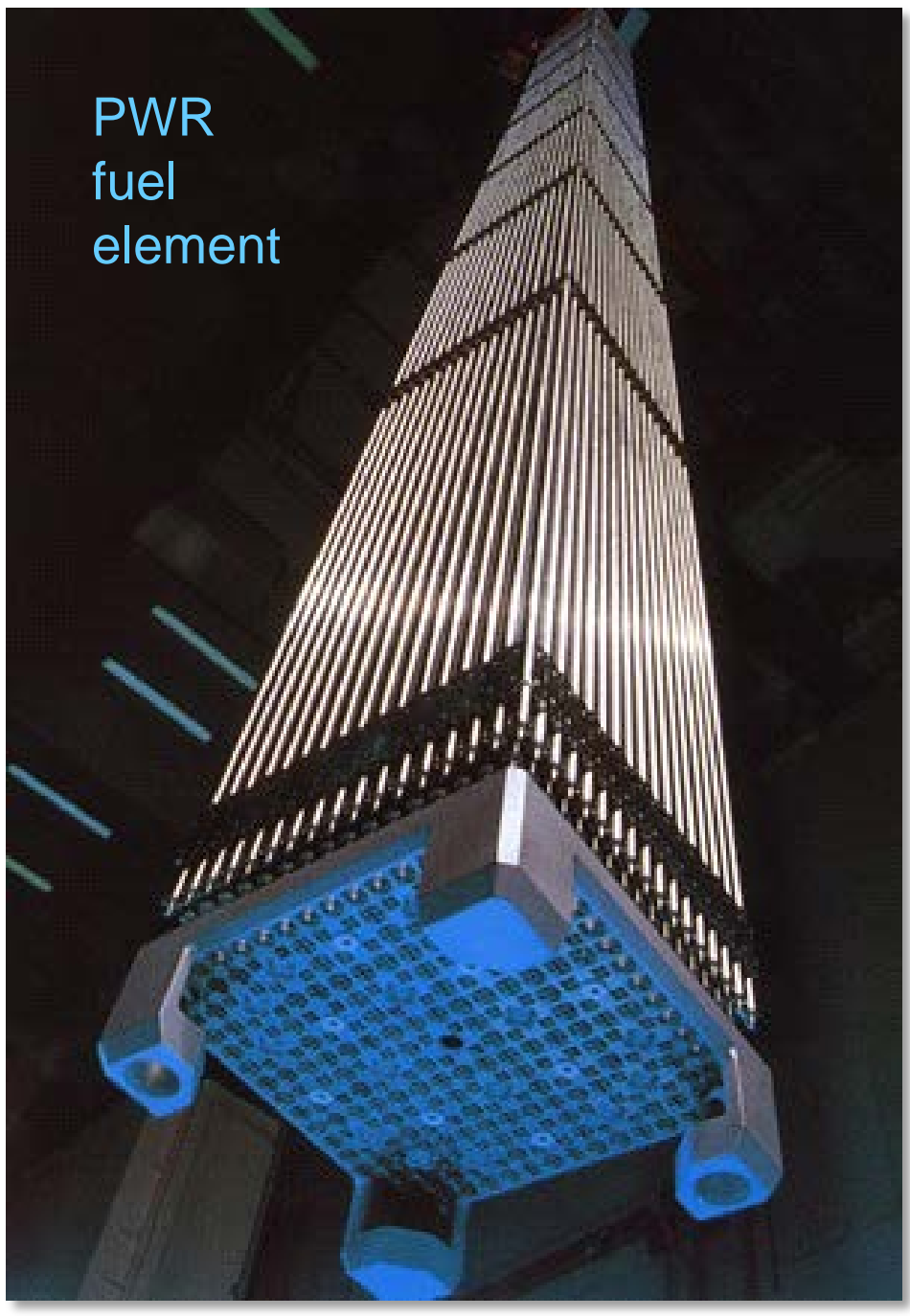




\section{Motivation}

Post-test appearance of Zry samples oxidized in various atmospheres

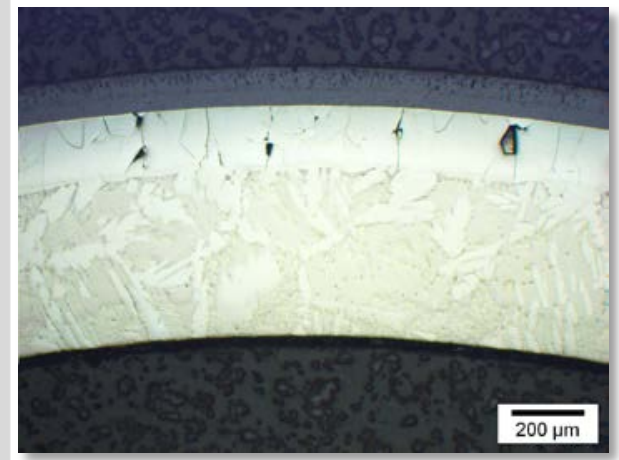

$20 \mathrm{~min}, 1200^{\circ} \mathrm{C}$, steam

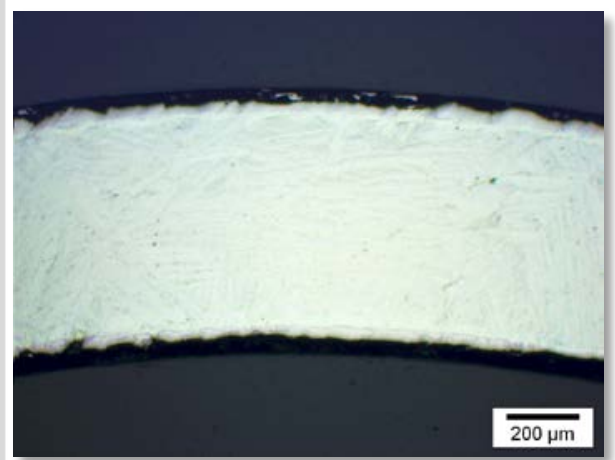

$3 \mathrm{~h}, 1200^{\circ} \mathrm{C}$, nitrogen

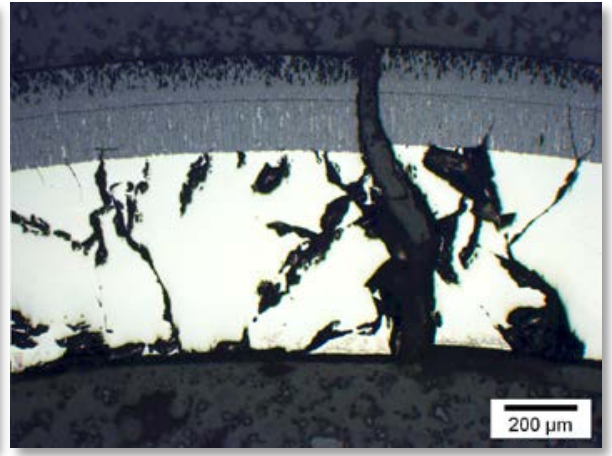

$3 \mathrm{~min}, 1600^{\circ} \mathrm{C}$, steam

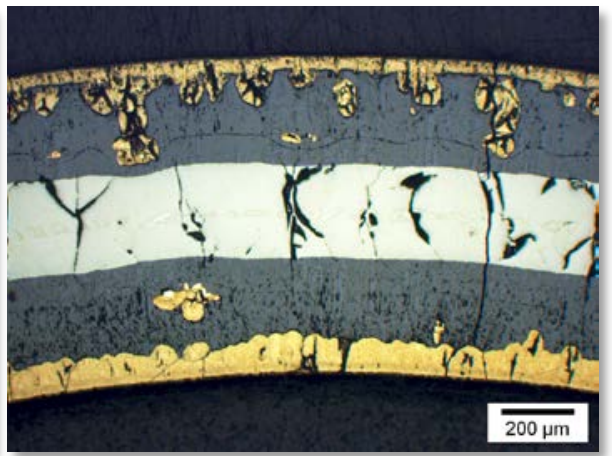

10 min $\mathrm{O}_{2}$, then $50 \mathrm{~min}$ $\mathrm{N}_{2}, 1200^{\circ} \mathrm{C}$

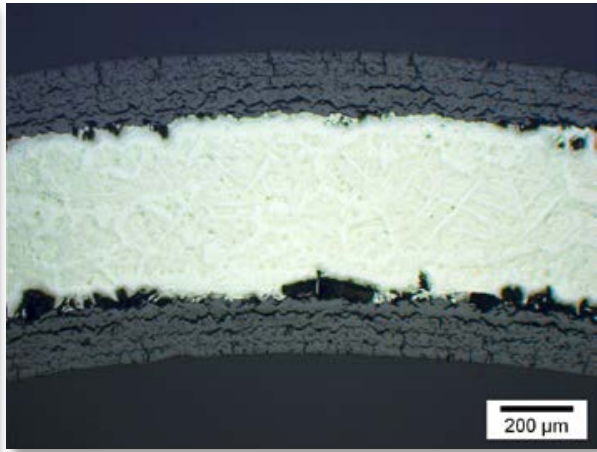

$1.5 \mathrm{~h}, 980^{\circ} \mathrm{C}$, steam

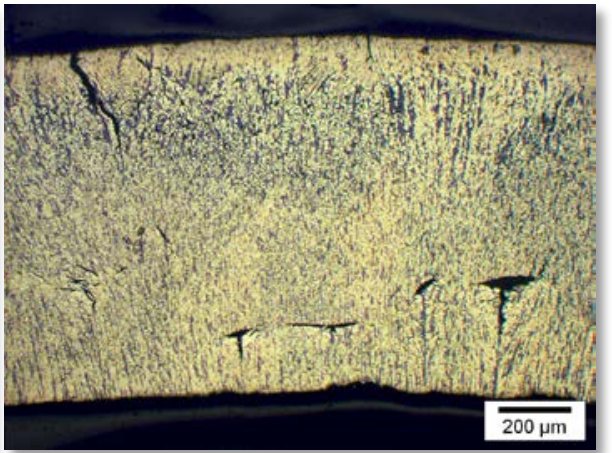

$\alpha-\operatorname{Zr}(0), 1 \mathrm{~h} \mathrm{~N}, 1200^{\circ} \mathrm{C}$

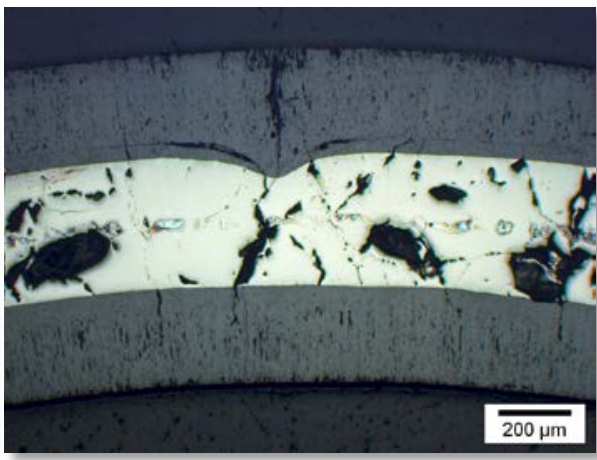

$1.5 \mathrm{~h}, 1200^{\circ} \mathrm{C}$, oxygen

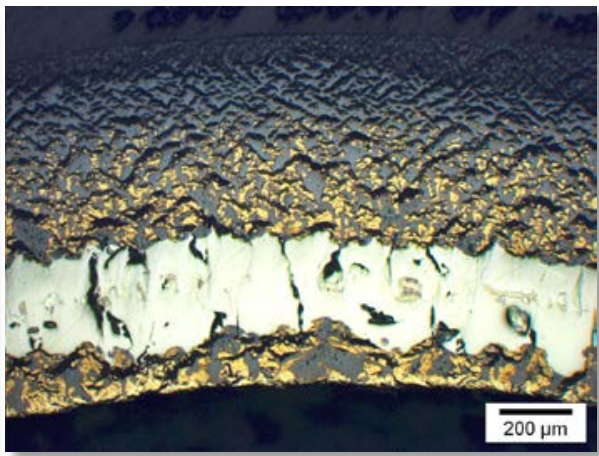

$15 \mathrm{~min}, 1200^{\circ} \mathrm{C}$, air

$\Rightarrow$ Very complex reaction behavior depending on conditions (temperature, atmosphere) 


\section{Experimental}

- Most tests were conducted in a NETZSCH STA409 coupled with steam injector and mass spectrometer; some in horizontal tube furnace with air lock

- Typical temperature range: $600-1600^{\circ} \mathrm{C}$

- Zr alloys:

Zry-4, Zry-2, Duplex DX-D4, M5 ${ }^{\circledR}$, E110, Zirlo ${ }^{\text {TM }}$

- Atmospheres: steam, oxygen, air, nitrogen, mixtures of these

- Mostly isothermal tests, some transient experiments
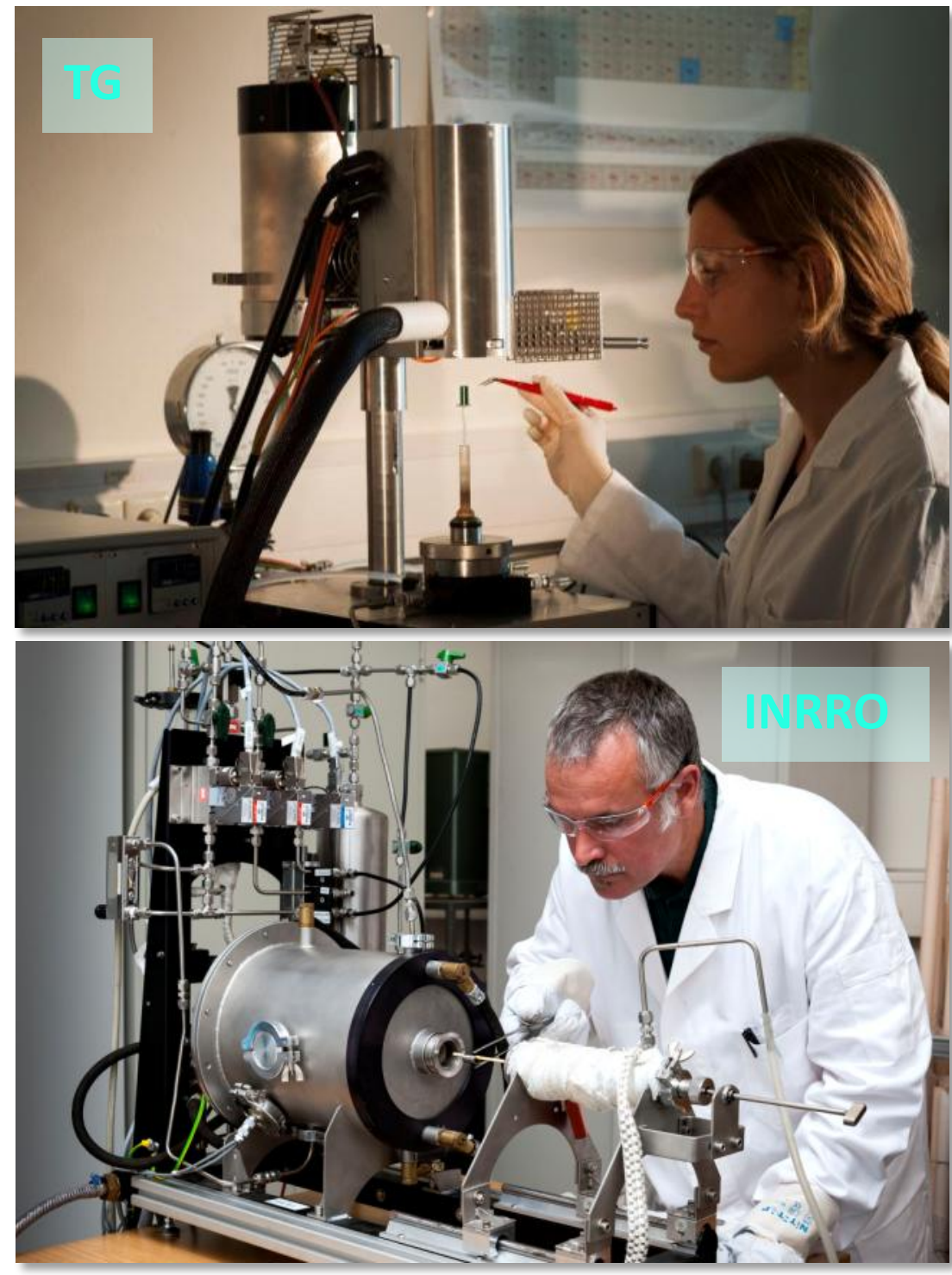


\section{Oxidation in steam (oxygen)}

- Most LOCA and SFD codes use parabolic oxidation correlations, (i.e. $\mathrm{n}=1 / 2$ in $\Delta m / S=k_{m} \cdot t^{n}$ )

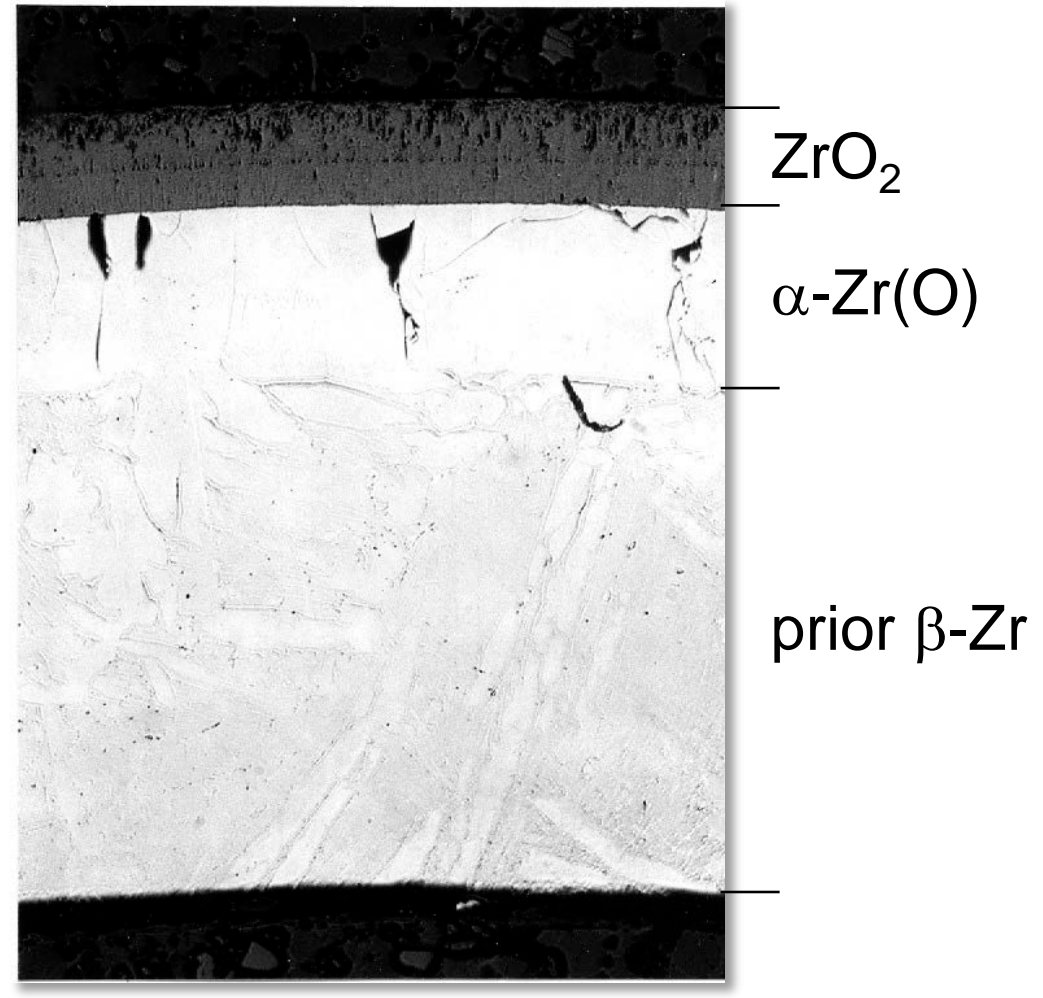

$1200^{\circ} \mathrm{C}$, quench

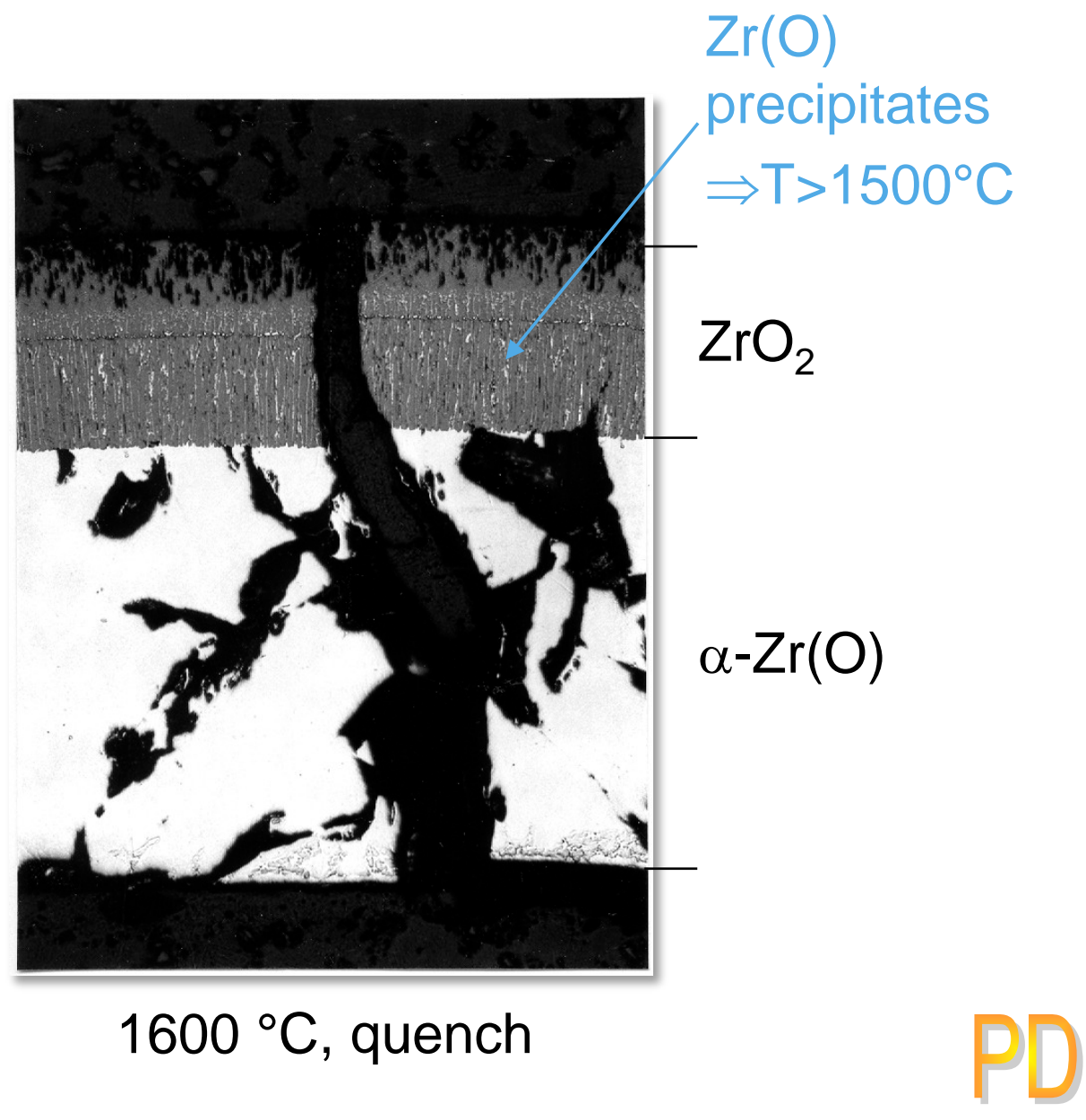




\section{Oxidation in steam (oxygen)}

- Deviations from parabolic kinetics at temperatures $<1100^{\circ} \mathrm{C}$

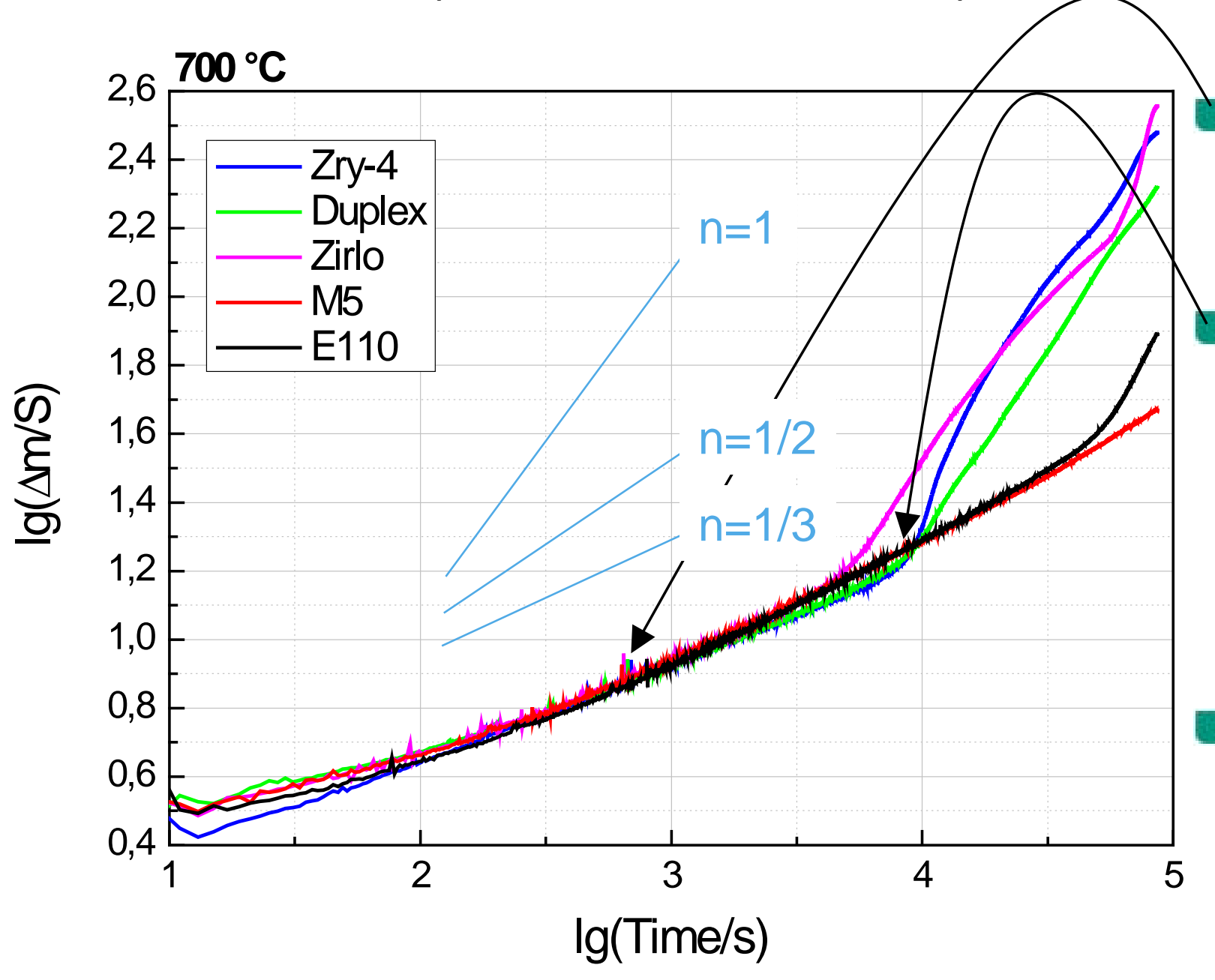

Sub-parabolic (cubic) kinetics

Transition from (sub-) parabolic to linear kinetics after critical time / oxide thickness due to breakaway

Similar kinetics of all alloys before transition, but strongly varying behavior at and after transition 


\section{Breakaway oxidation}

Loss of protective properties of oxide scale due to its mechanical failure.

- Breakaway is caused by phase transformation from meta-stable tetragonal to monoclinic oxide and corresponding change in density up to ca. $1050^{\circ} \mathrm{C}$.

- Critical times and oxide thicknesses for breakaway strongly depend on type of alloy and boundary conditions (ca. $30 \mathrm{~min}$ at $1000^{\circ} \mathrm{C}$ and $8 \mathrm{~h}$ at $600^{\circ} \mathrm{C}$ ).

- During breakaway significant amounts of hydrogen can be absorbed ( $>40$ at.\%, 7000 wppm) due to local enrichment of $\mathrm{H}_{2}$ in pores and cracks near the metal/oxide interface (“hydrogen pump").

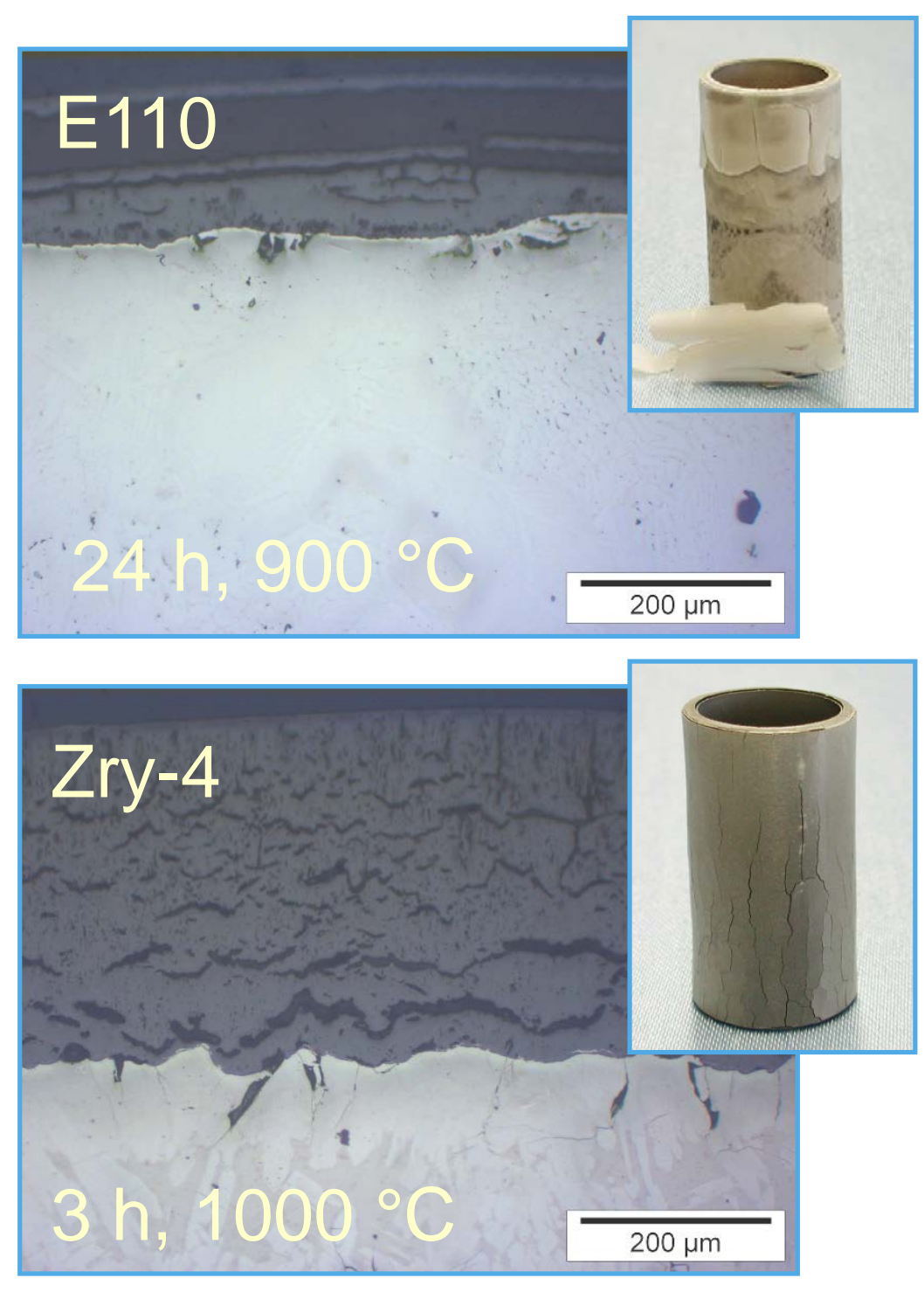


Transition times (h) and corresponding critical oxide scale thickness $(\mu \mathrm{m})$ during oxidation in steam

\begin{tabular}{|c|c|c|c|c|c|}
\hline $\mathrm{T},{ }^{\circ} \mathrm{C}$ & Zircaloy-4 & Duplex-D4 & Zirlo $^{\mathrm{TM}}$ & $\mathrm{M5}^{\circ}$ & E110 \\
\hline 600 & $8.2(7)$ & $7.7(3)$ & $6.3(8)$ & nt & $\mathrm{nt}$ \\
\hline 700 & $2.2(9)$ & $2.2(9)$ & $1.4(9)$ & $\mathrm{nt}$ & $13(21)$ \\
\hline 800 & $7.4(41)$ & 7.3 (35) & $5.2(32)$ & $\mathrm{nt}$ & 0.9 (12) \\
\hline 900 & $1.3(40)$ & $1.4(38)$ & $2.1(40)$ & $\mathrm{nt}$ & $0.8(24)$ \\
\hline 1000 & 0.6 (89) & 0.9 (105) & $0.6(76)$ & $\mathrm{nt}$ & $0.6(48)$ \\
\hline$\geq 1100$ & nt & nt & nt & $\mathrm{nt}$ & $\mathrm{nt}$ \\
\hline
\end{tabular}
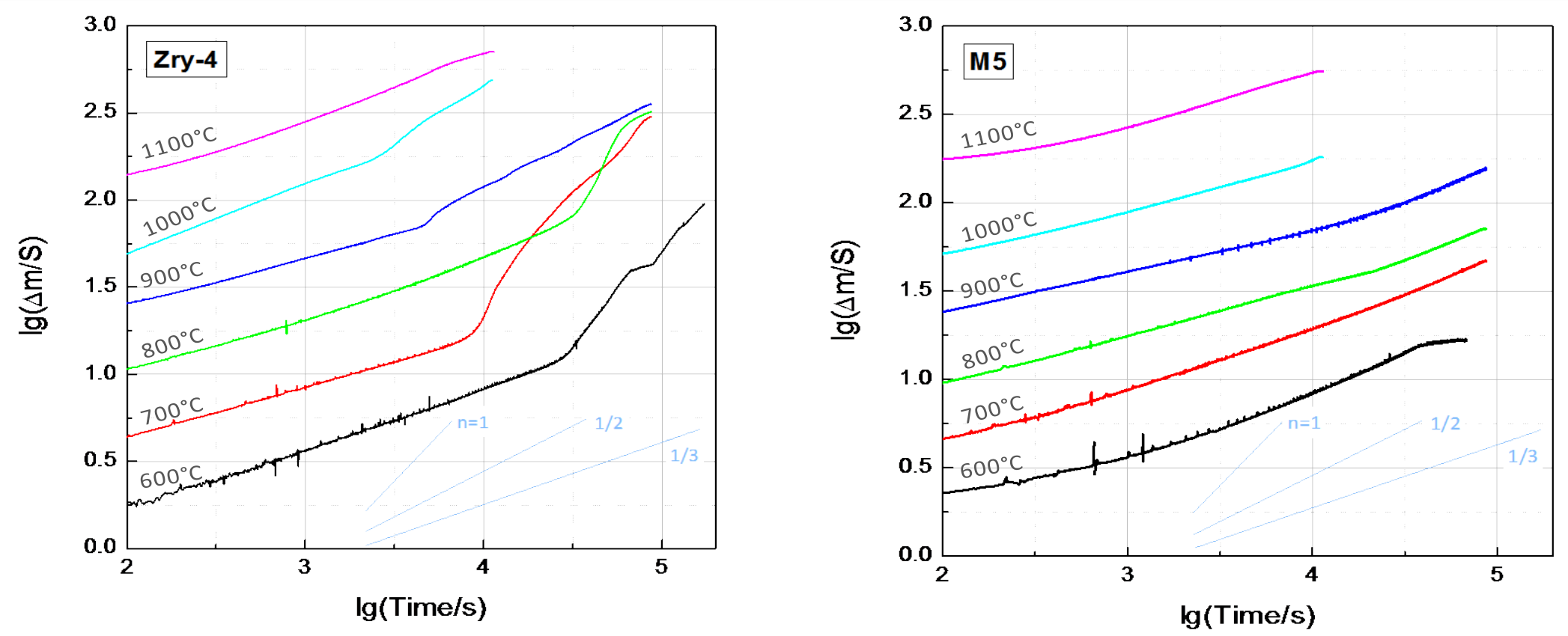


\section{Correlation of $\mathrm{H}$ absorption and oxide morphology}

In-situ NR of $\mathrm{H}$ uptake during oxidation of Zry-4 at $1000^{\circ} \mathrm{C}$ in steam
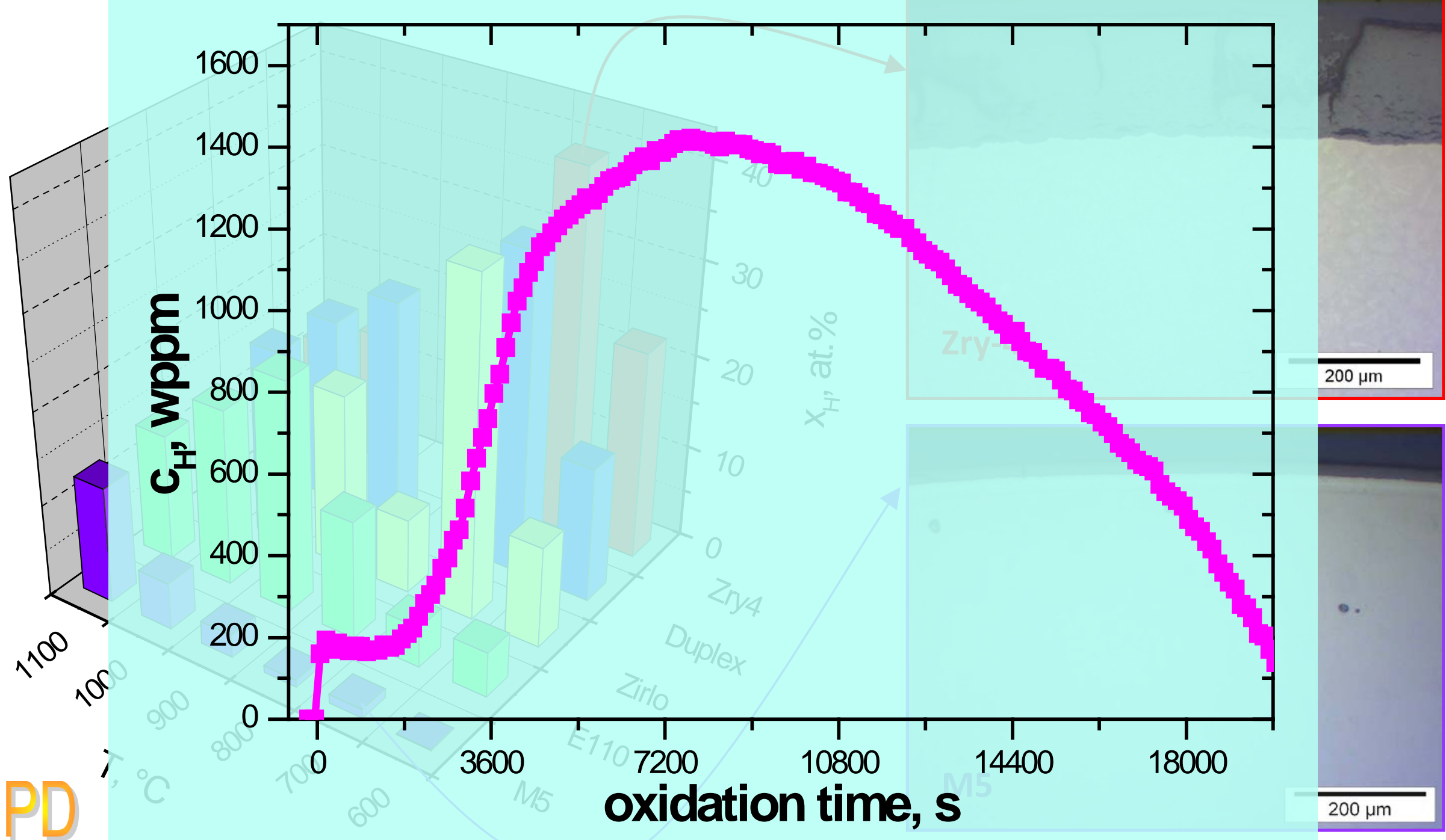


\section{Oxidation in atmospheres containing nitrogen}

Late phase after RPV failure

- Air ingress reactor core, spent fuel pond, or transportation cask

- Nitrogen in BWR containments (inertization) and ECCS pressurizers

- Prototypically following steam oxidation and mixed with steam

- Consequences:

- Significant heat release causing temperature runaway from lower temperatures than in steam

- Strong degradation of cladding causing early loss of barrier effect

- High oxygen activity influencing FP chemistry and transport

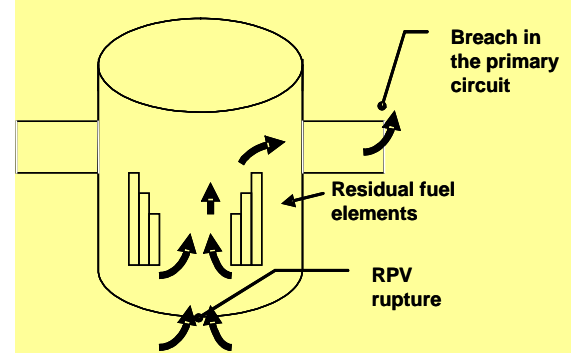

Mid loop operation

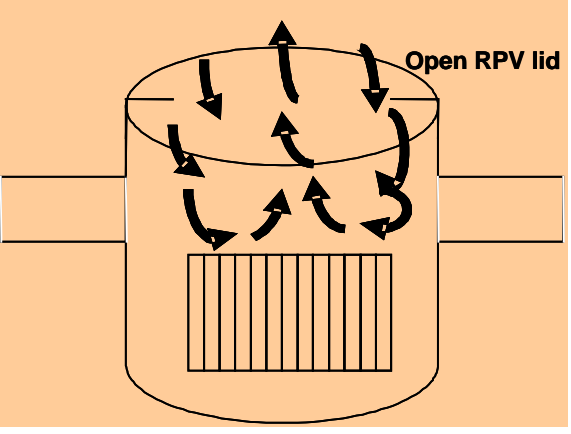

Spent fuel storage pool accident

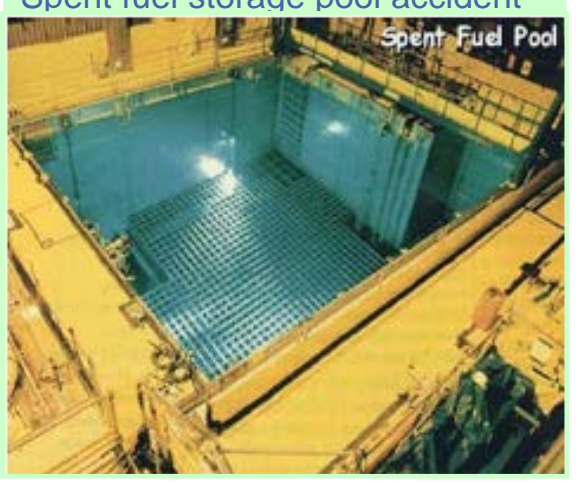




\section{Oxidation of $\mathrm{Zr}$ alloys in $\mathrm{N}_{2}, \mathrm{O}_{2}$ and air}

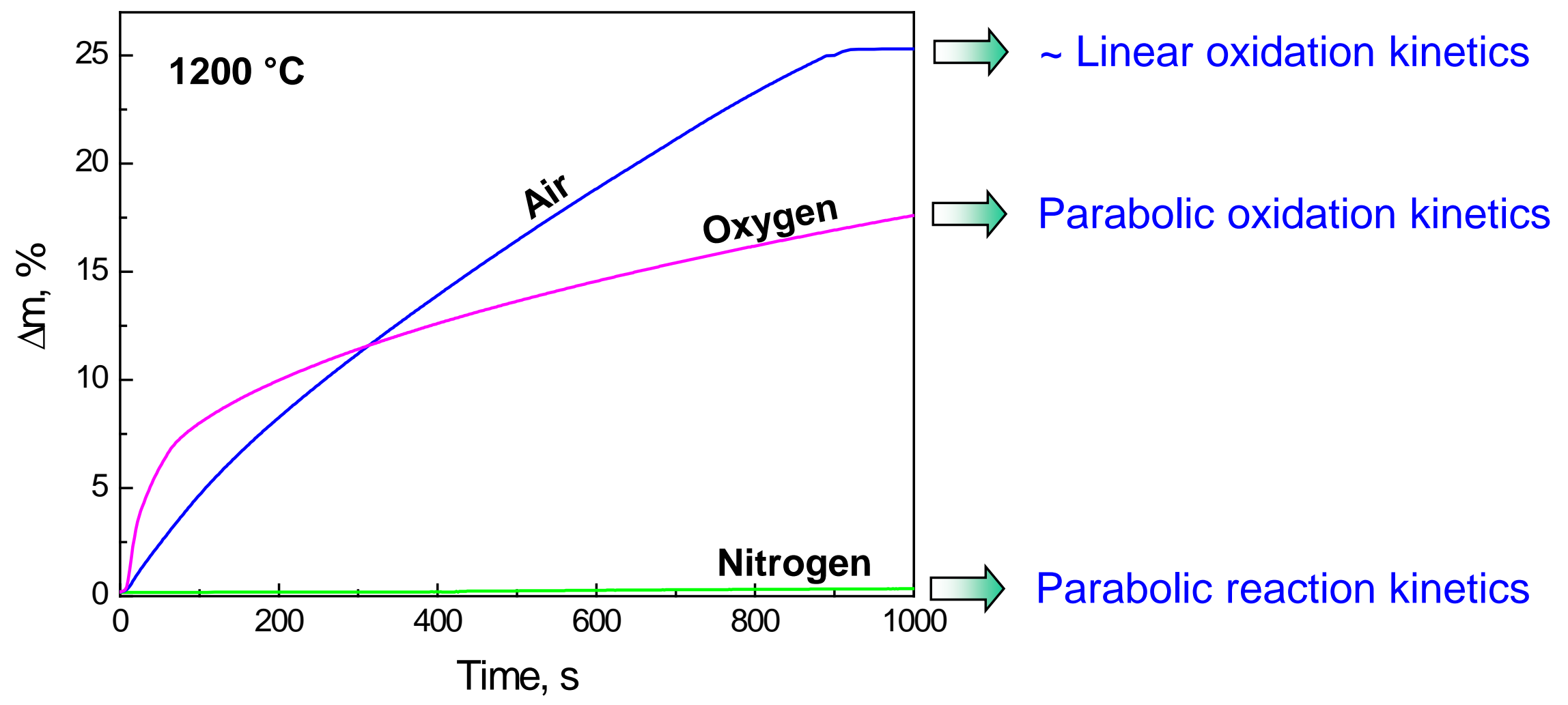

Oxidation rate in air is much higher than in oxygen or steam 


\section{Oxidation of $\mathrm{Zr}$ alloys in $\mathrm{N}_{2}, \mathrm{O}_{2}$ and air}

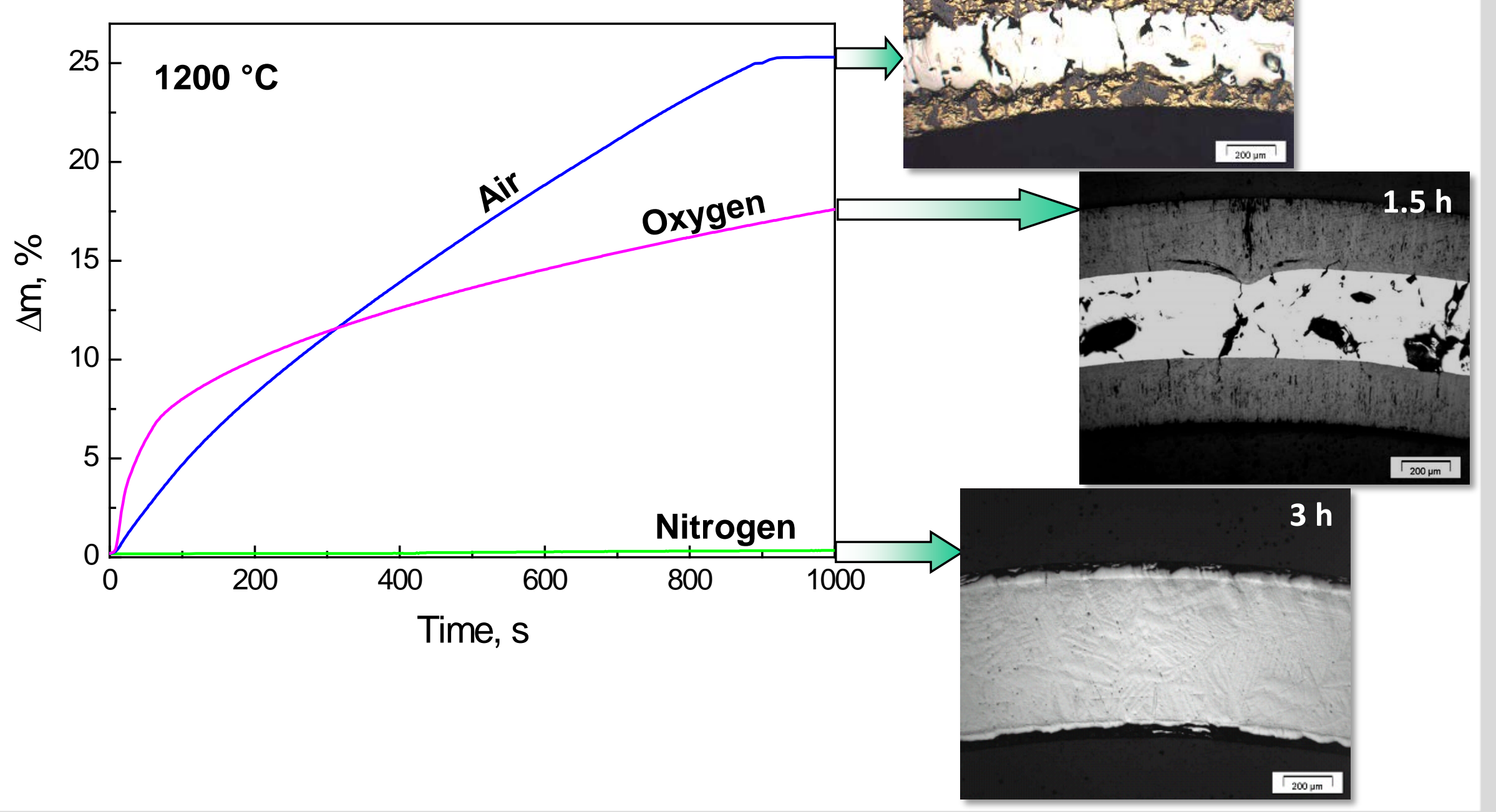




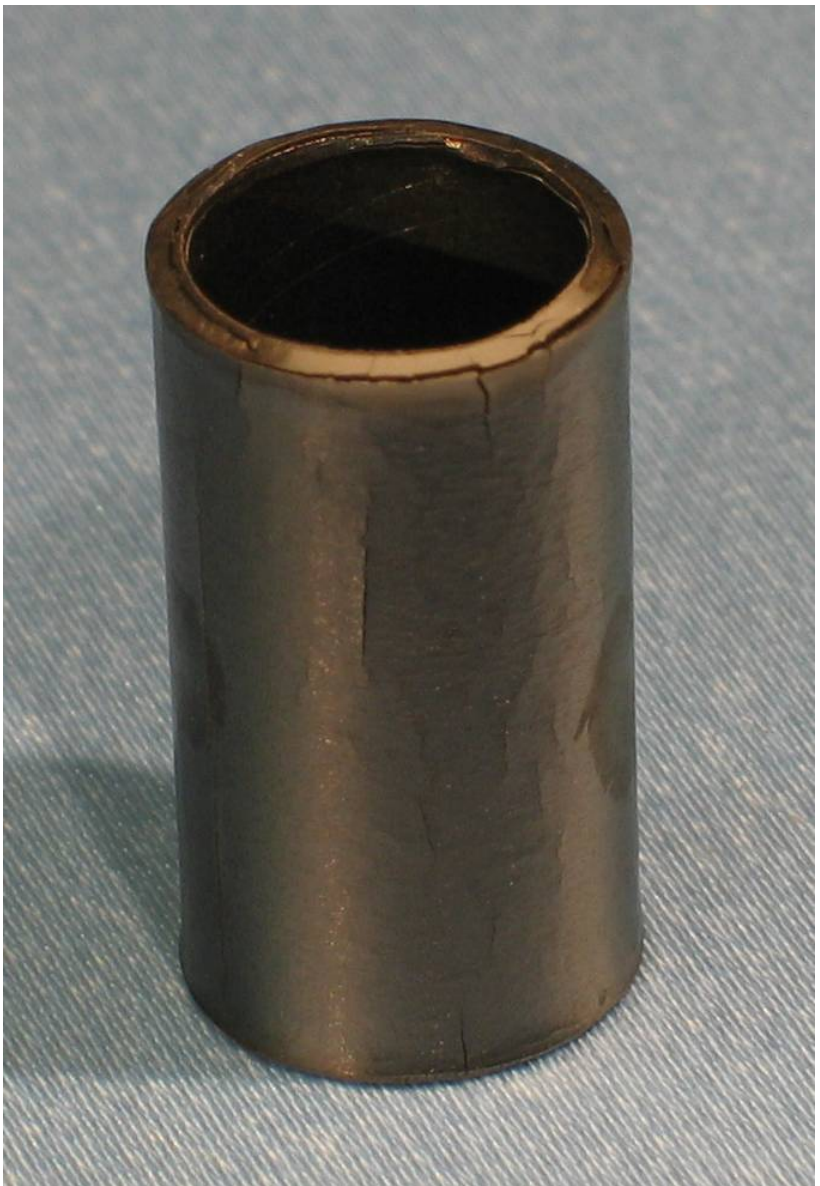

1 hour at $1200^{\circ} \mathrm{C}$ in steam

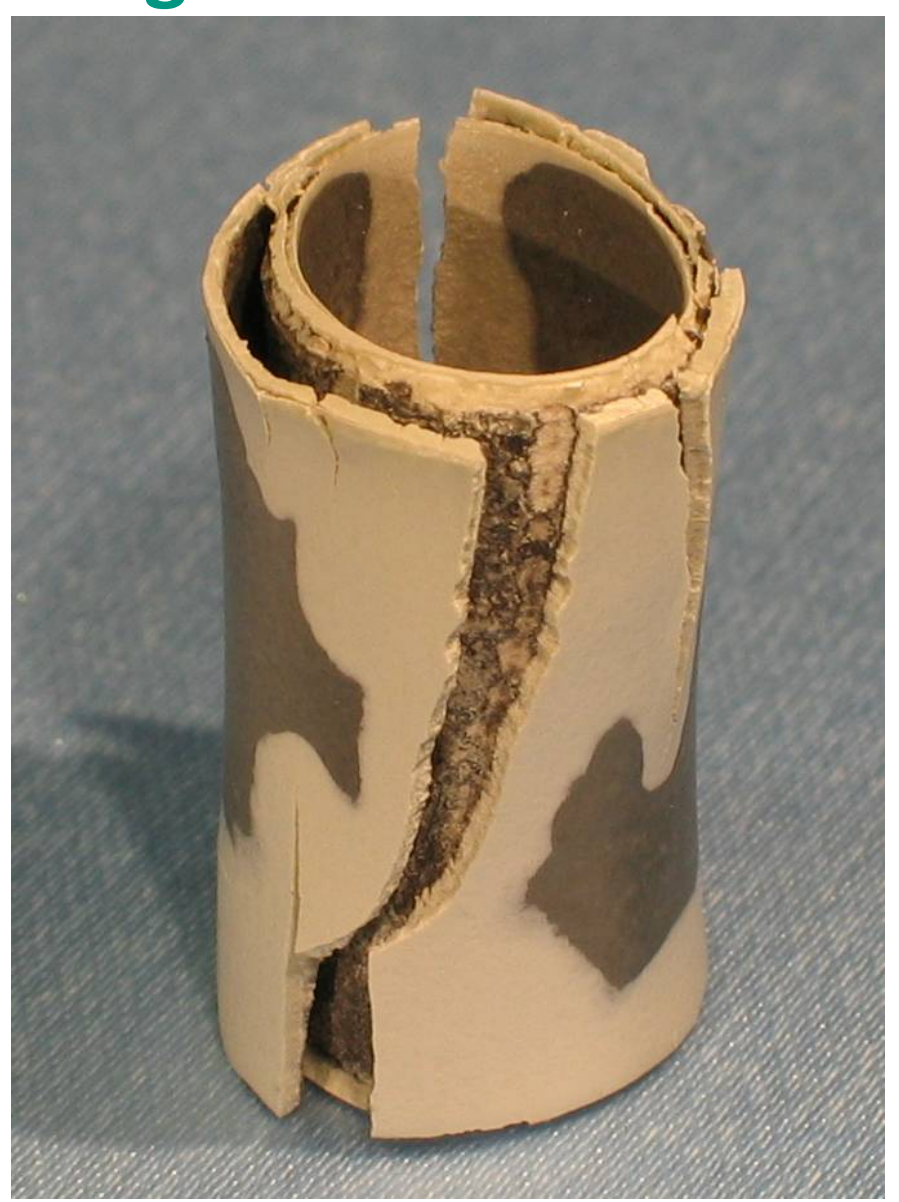

1 hour at $1200^{\circ} \mathrm{C}$ in air

\section{Loss of barrier effect of cladding}




\section{Mechanism of air oxidation}

- Diffusion of air through imperfections in the oxide scale to the metal/oxide interface

- Consumption of oxygen

- Remaining nitrogen reacts with zirconium and forms $\mathrm{ZrN}$

- $\mathrm{ZrN}$ is re-oxidized by fresh air with progressing reaction associated with a volume increase by $48 \%$

- Formation of porous and nonprotective oxide scales

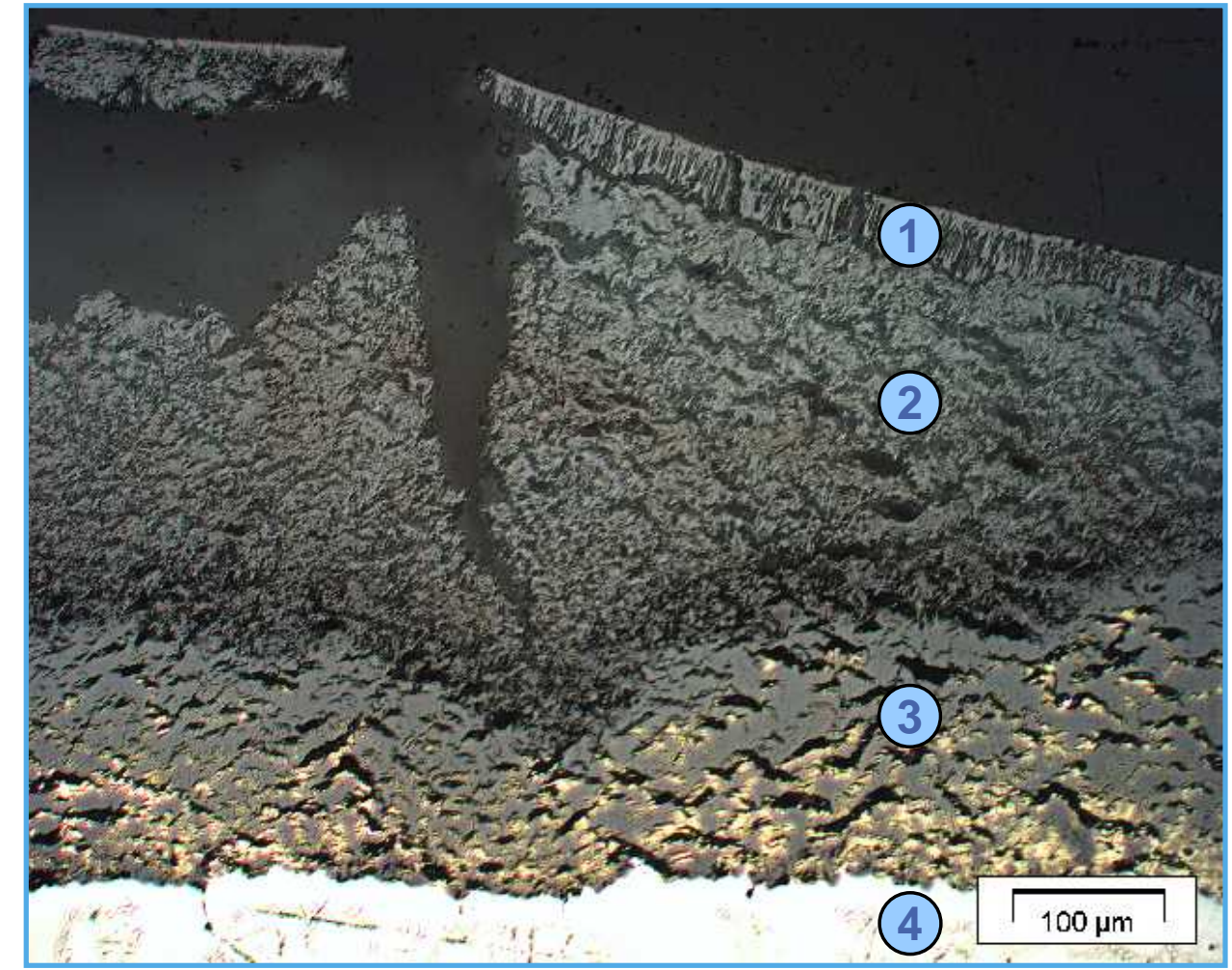

1 - initially formed dense oxide $\mathrm{ZrO}_{2}$

2 - porous oxide after oxidation of $\mathrm{ZrN}$

$3-\mathrm{ZrO}_{2} / \mathrm{ZrN}$ mixture

$4-\alpha-\operatorname{Zr}(O)$ 


\section{Reaction of $\mathrm{ZrO}_{\mathrm{x}}$ with nitrogen}
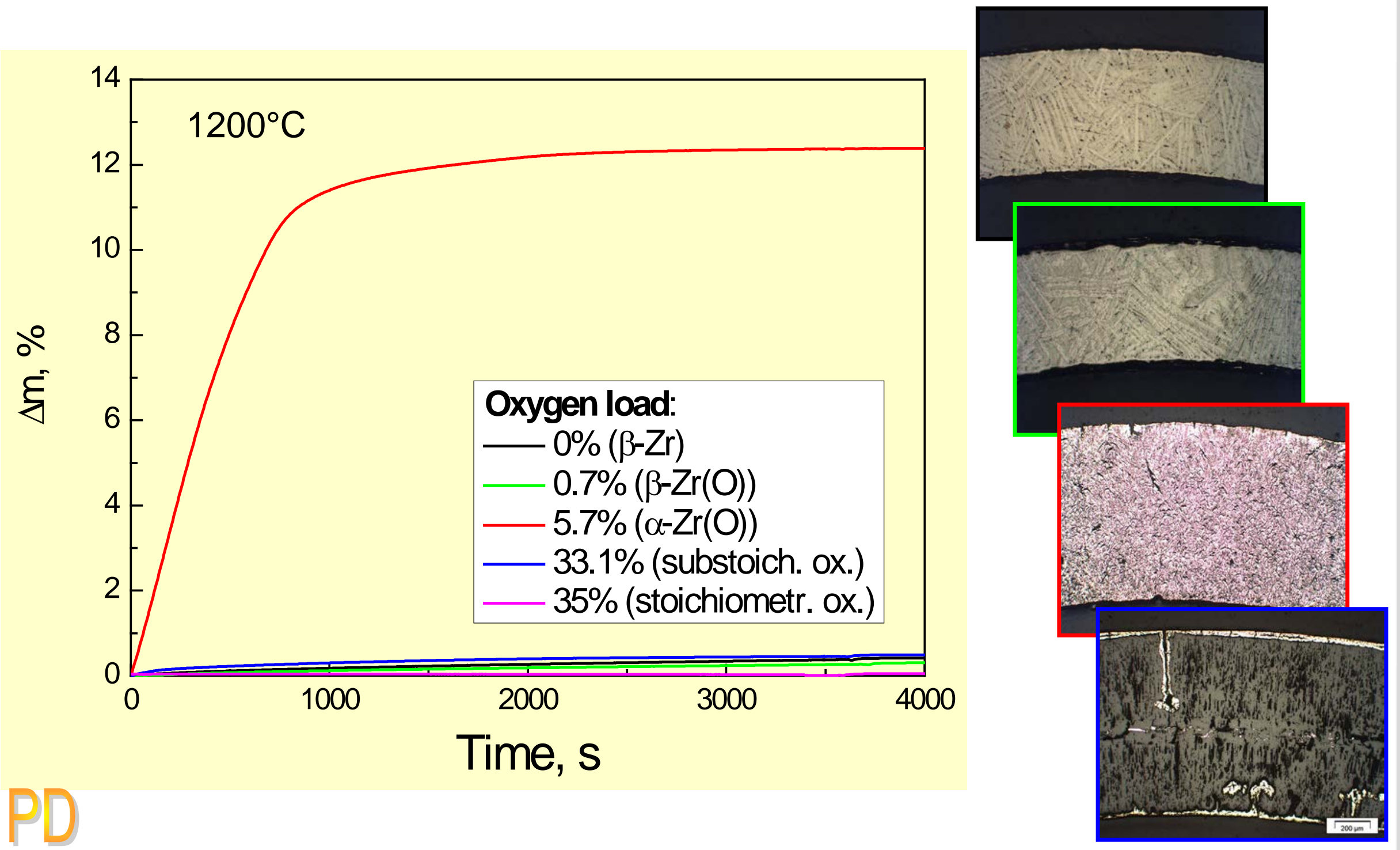
Influence of pre-oxidation (PO) in steam on subsequent reaction in air and nitrogen

Example: Zry-4, $1200^{\circ} \mathrm{C}$
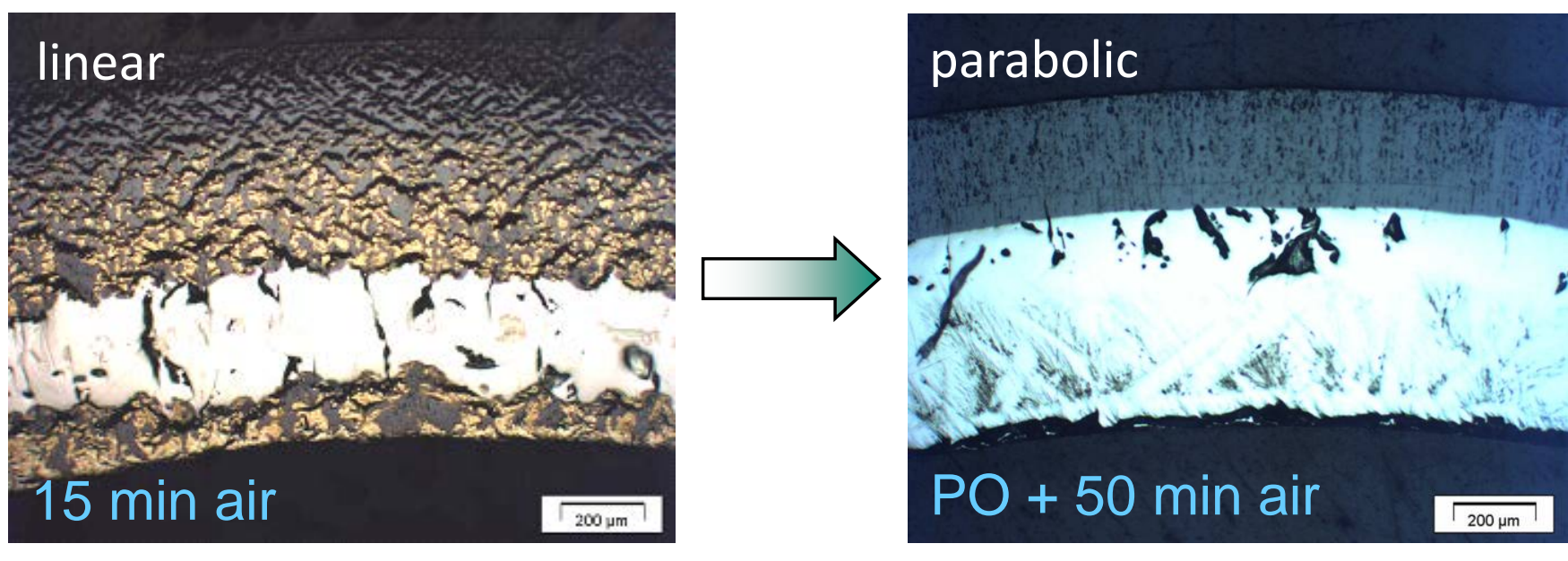

Protective effect of PO on subsequent oxidation in air as long as oxide scale is intact
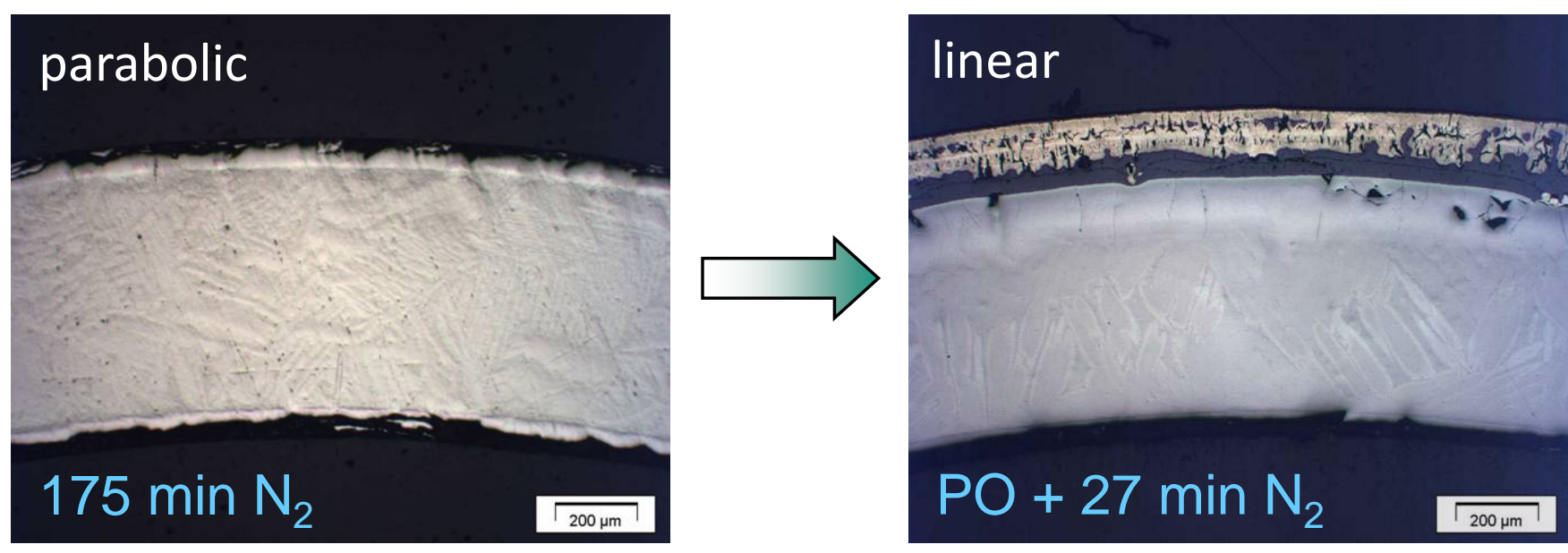

Accelerating effect of $\mathrm{PO}$ on subsequent reaction in nitrogen 


\section{Oxidation of $\mathrm{Zr}$ alloys in various atmospheres}

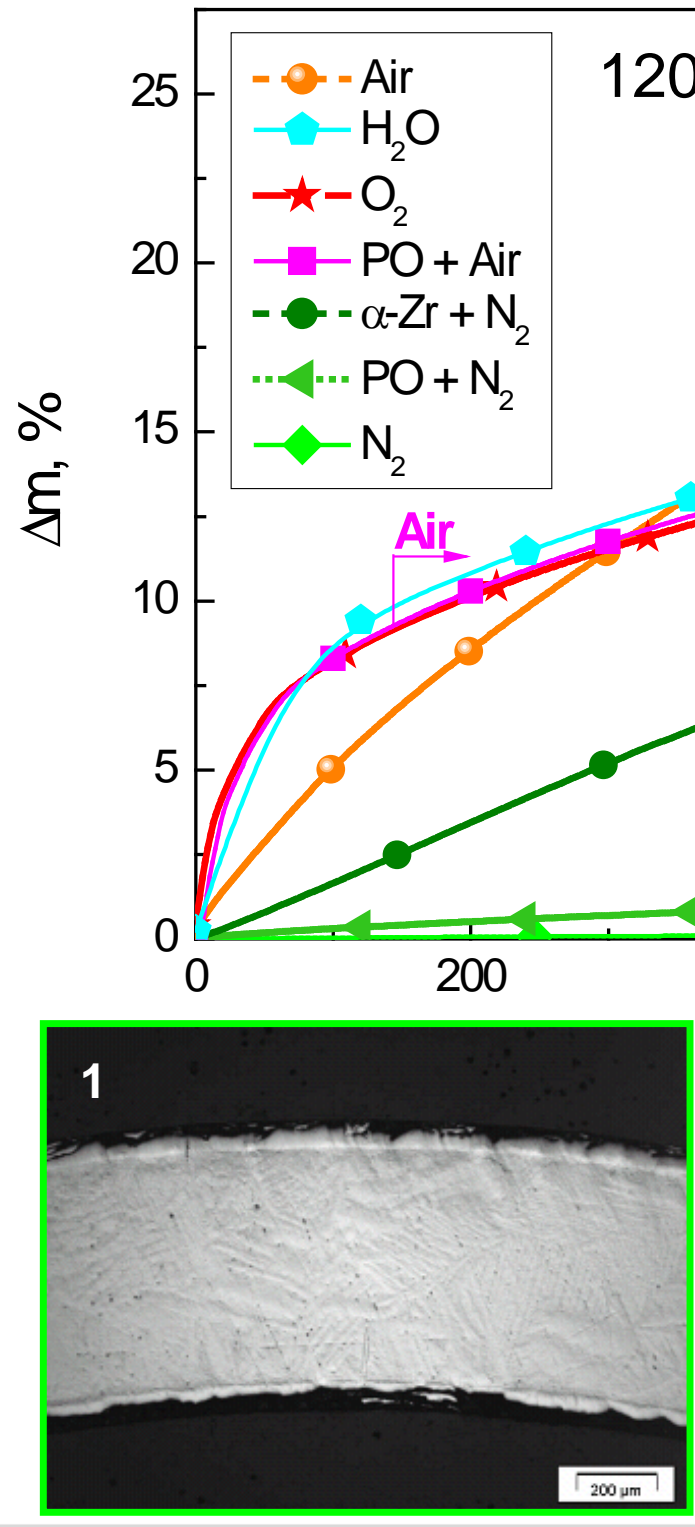

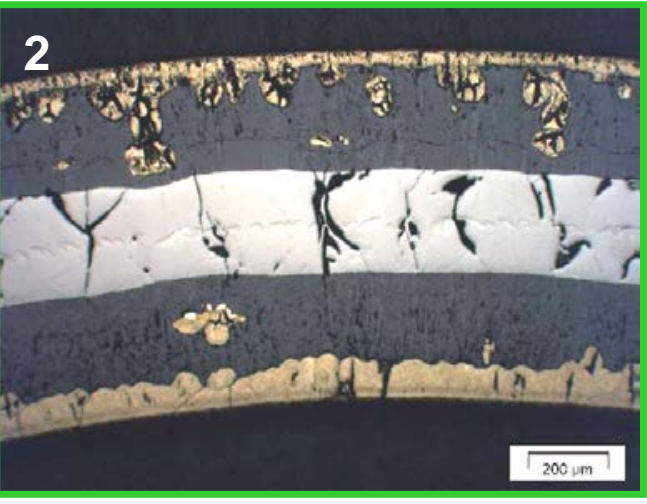

ASTM Zr in Nucl. Ind. 2013
N $\mathbf{S I T}$
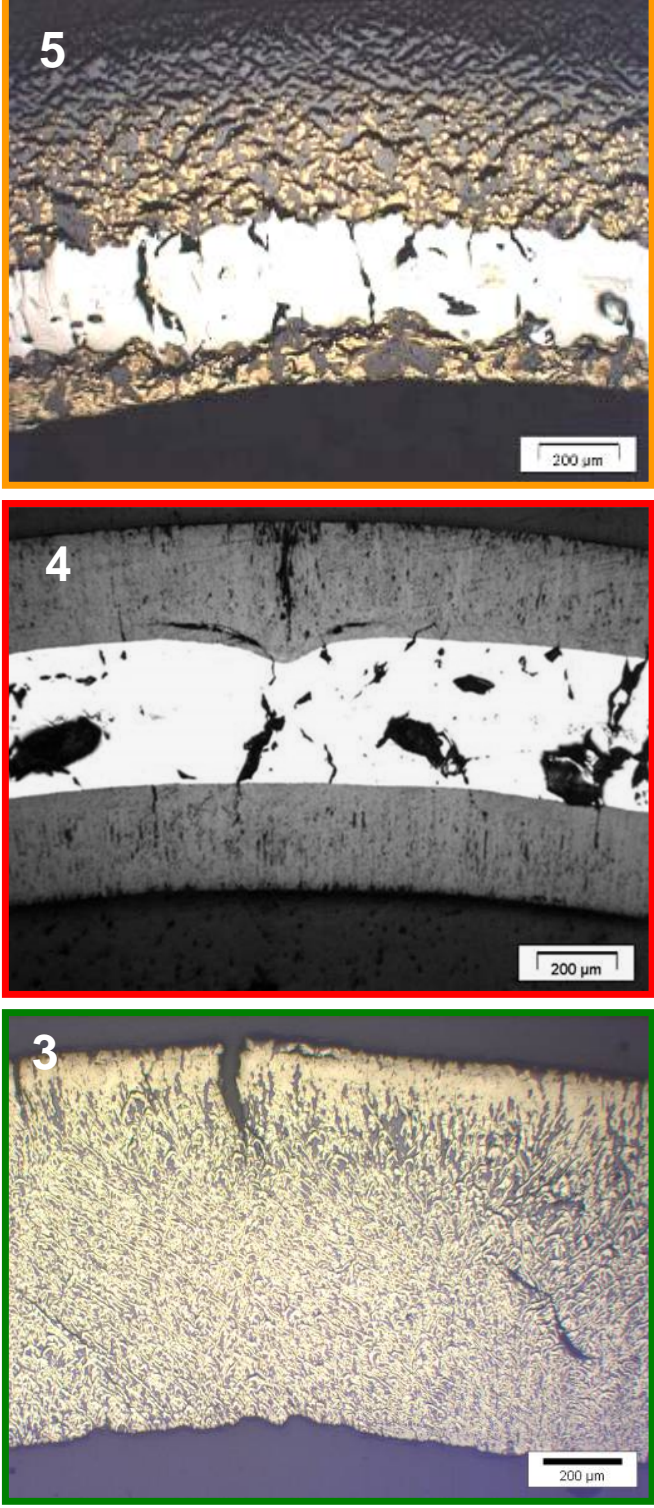

Institute for Applied Materials 


\section{Oxidation of $\mathrm{Zr}$ alloys in various atmospheres}

\begin{tabular}{|l|c|c|}
\hline \multicolumn{1}{|c|}{ Reaction of Zry-4 in } & Kinetic rate law & Relative reaction rate, a.u. \\
\hline $\mathrm{N}_{2}$ & parabolic & 1 \\
\hline $\mathrm{N}_{2}$ after pre-oxidation in $\mathrm{O}_{2}$ & linear & 10 \\
\hline $\mathrm{N}_{2}$ with oxygen-stabilized $\alpha-\mathrm{Zr}(\mathrm{O})$ & linear & 70 \\
\hline $\mathrm{O}_{2}, \mathrm{H}_{2} \mathrm{O}$ & parabolic & 100 \\
\hline Air after pre-oxidation in $\mathrm{O}_{2}$ & parabolic & 100 \\
\hline Air & linear & 150 \\
\hline
\end{tabular}

* at $1200^{\circ} \mathrm{C}$ 
Oxidation in mixed steam-air atmospheres

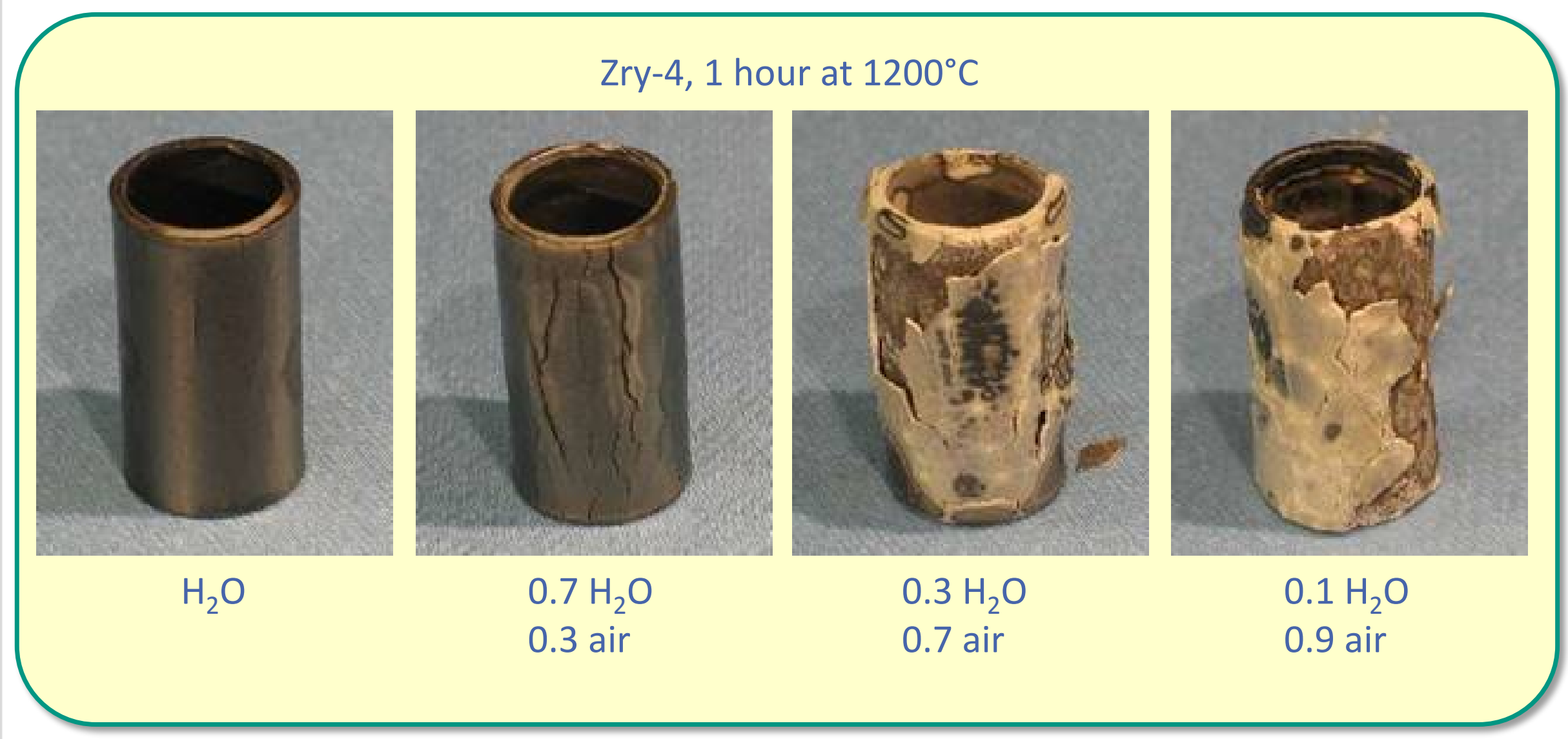

$\Rightarrow$ Increasing degradation with raising content of air in the mixture 
Oxidation in mixed atmospheres

1 hour at $1000{ }^{\circ} \mathrm{C}$ in steam

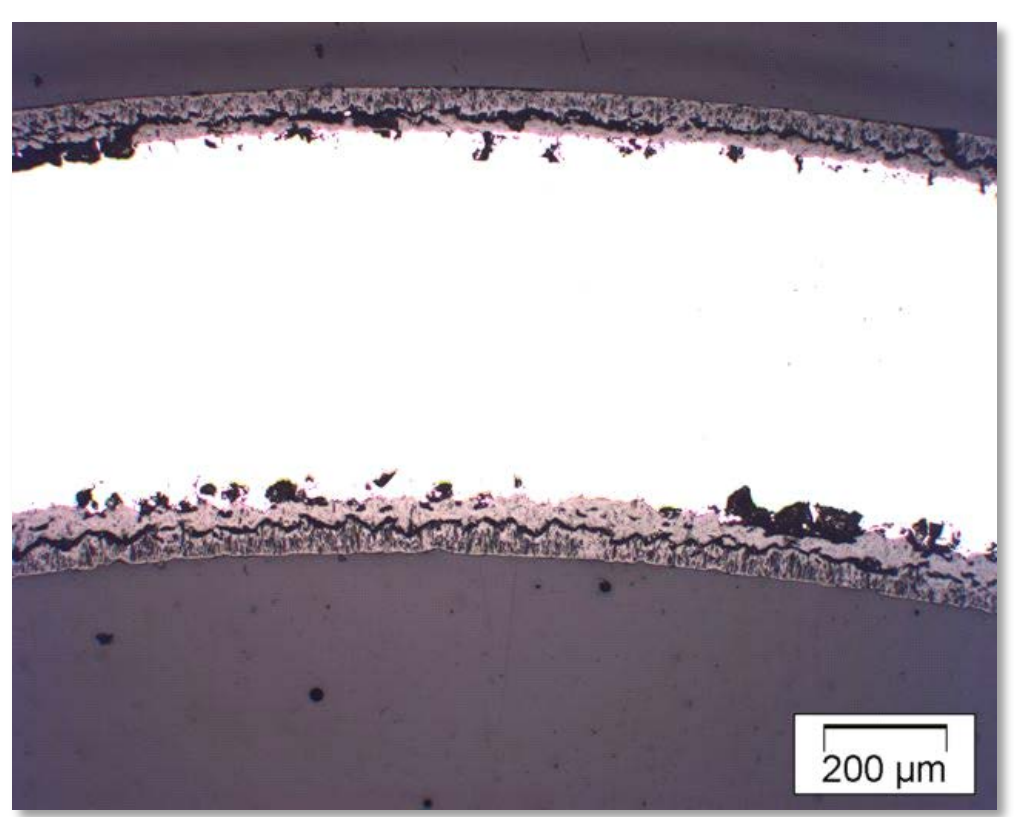

1 hour at $1000^{\circ} \mathrm{C}$ in 50/50 steam/ $\mathrm{N}_{2}$

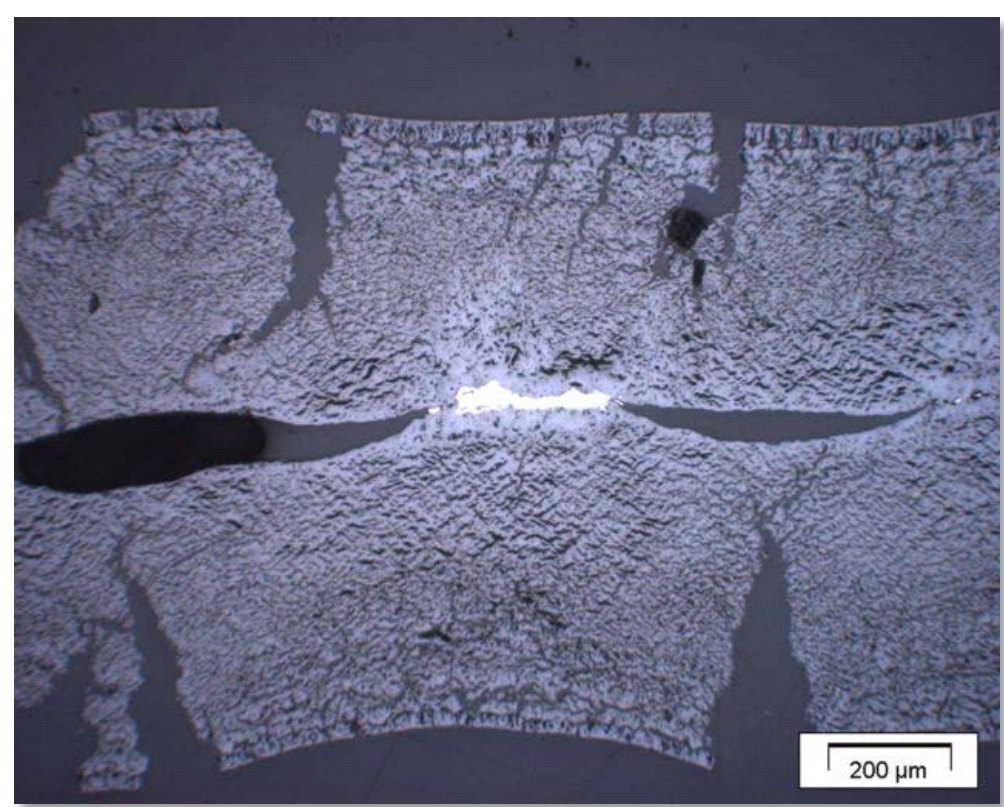

- Strong effect of nitrogen on oxidation and degradation

- Nitrogen acts like a catalyst (NOT like an inert gas)

- Enhanced hydrogen source term by oxidation in mixtures containing nitrogen 


\section{Conclusions}

- The usually applied parabolic oxidation kinetics are, strictly speaking, only valid at temperatures above $1000^{\circ} \mathrm{C}$ and for fast transients (with fast passing of the breakaway region).

- Sub-parabolic kinetics is observed at temperatures below $1000^{\circ} \mathrm{C}$.

- Breakaway has to be taken into account for slow transients and long duration scenarios at medium temperatures $\left(600-1000^{\circ} \mathrm{C}\right)$.

- Nitrogen is not an inert gas under the conditions of a nuclear accident. It accelerates oxidation and causes rather linear kinetics.

- Computer codes simulating severe accident scenarios should take into account non-parabolic oxidation kinetics. Various activities are ongoing worldwide. 
$\mathbb{N} \mathbf{K}$ IT

Karlsruhe Institute of Technology

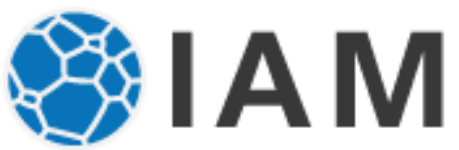

Institute for Applied Materials

\section{Deviations from the parabolic kinetics during oxidation of zirconium alloys}

Martin Steinbrück, Mirco Große

Karlsruhe Institute of Technology, Institute for Applied Materials, Germany

17th International Symposium on Zirconium in the Nuclear Industry, 03.-07.02.2013, Hyderabad, India

Institute for Applied Materials IAM-AWP \& Program NUKLEAR
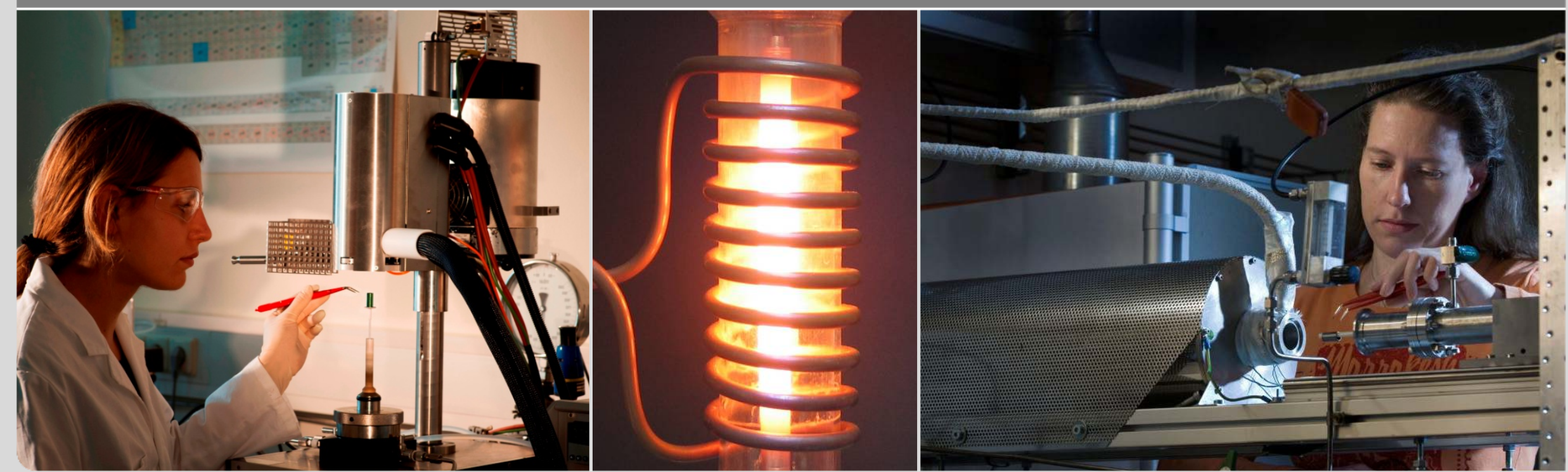

KIT - University of the State of Baden-Wuerttemberg and 


\section{Phase diagram $\mathrm{Zr}$ - $\mathrm{O}$}

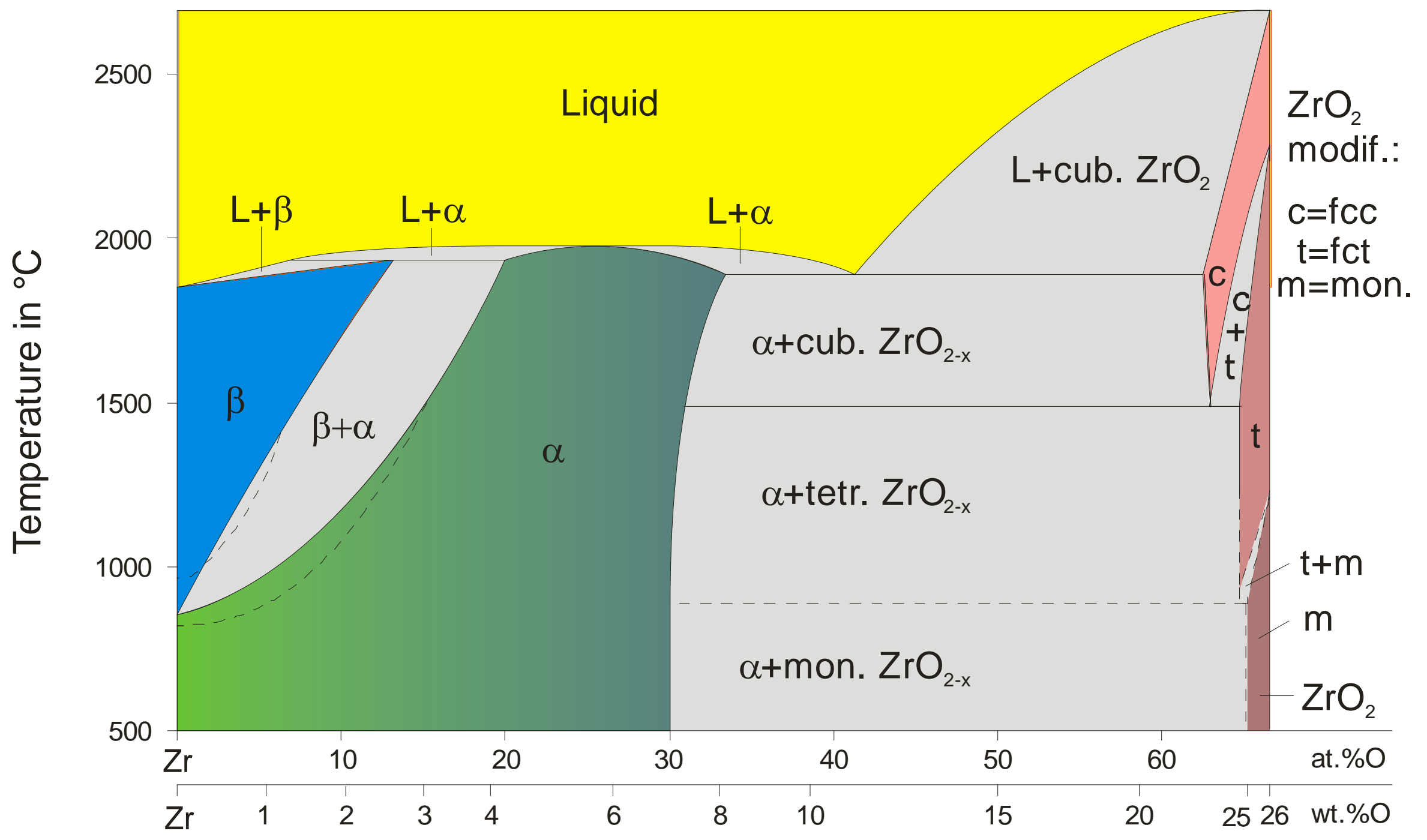




\section{Phase diagram Zr - 0}

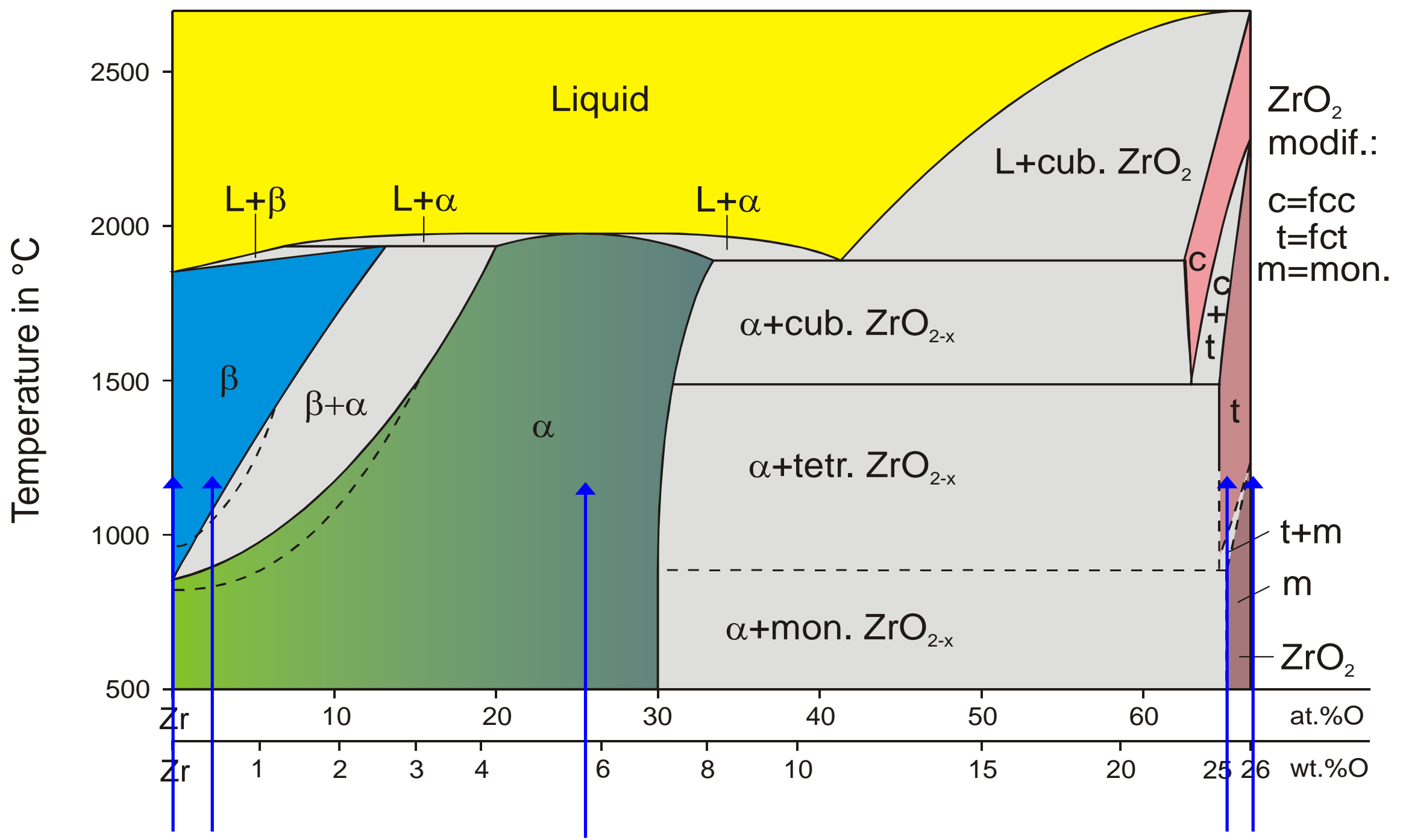




\section{Phase diagram $\mathrm{Zr}$ - H}

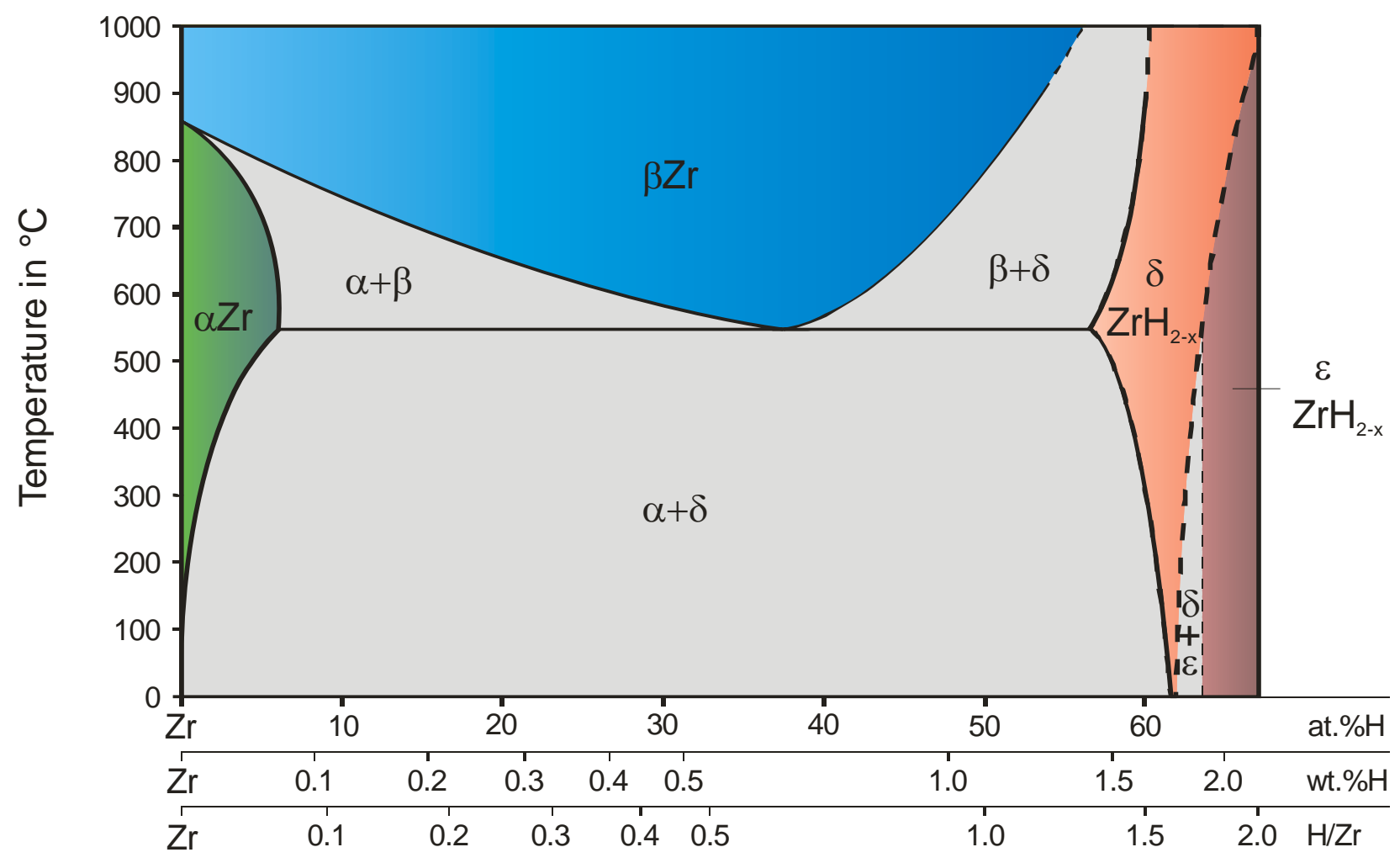

\section{Sieverts' law:}

$$
\frac{H}{Z r}=k_{S} \cdot \sqrt{p_{H_{2}}}
$$

with

$k_{S}=A \cdot e^{\frac{-B}{R T}}$ 


\section{Reaction of $\alpha-\operatorname{Zr}(0)$ with nitrogen}

\section{$1200{ }^{\circ} \mathrm{C}, 6.5 \mathrm{wt} \% \mathrm{O}$}

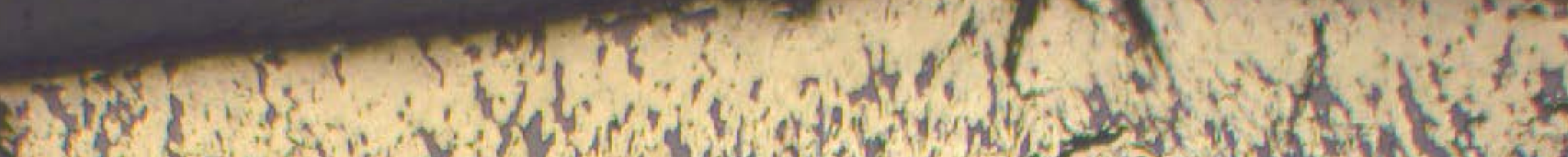

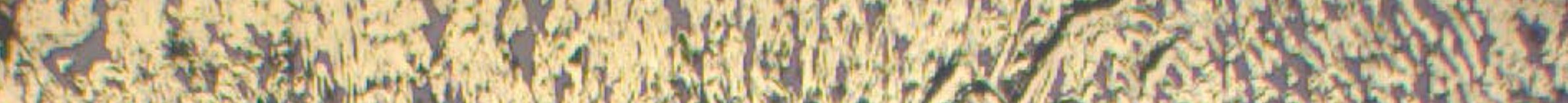
3 s.

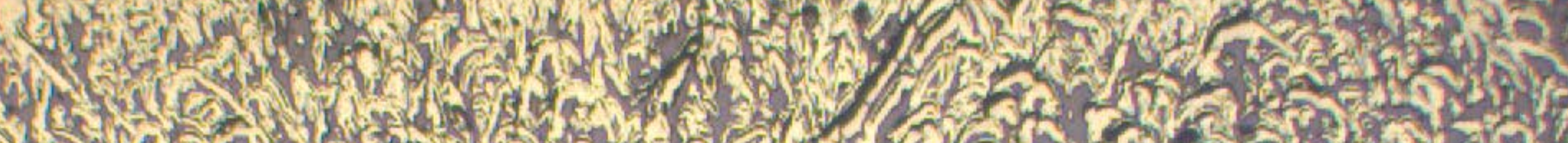

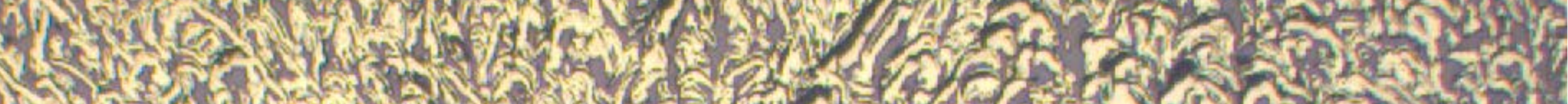

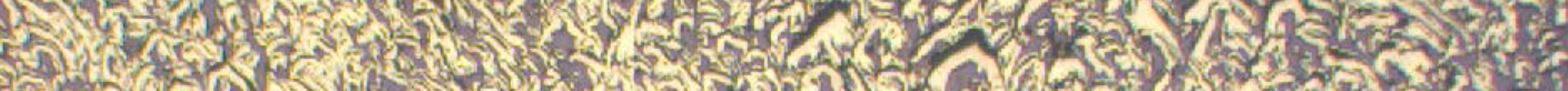

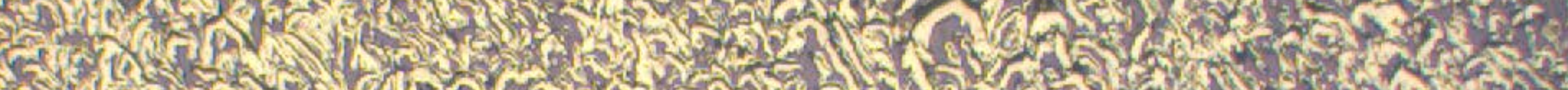

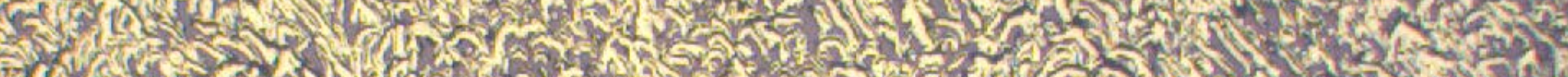
3 (1) 32,5 .

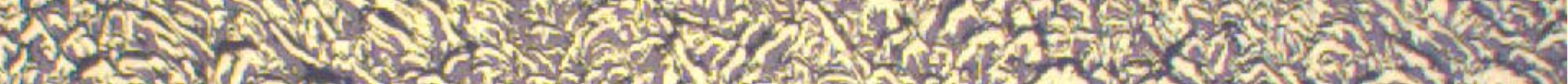

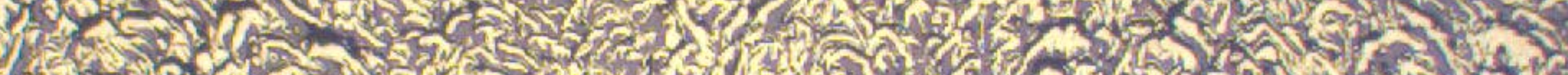

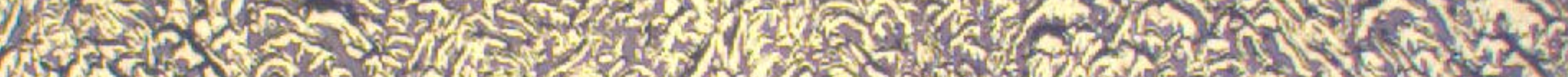

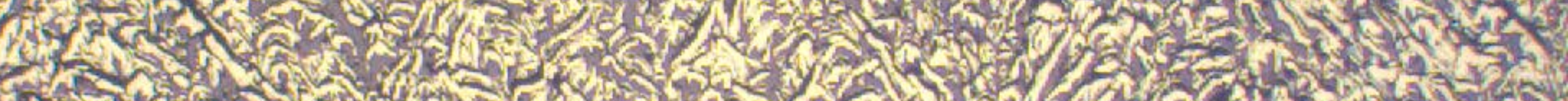

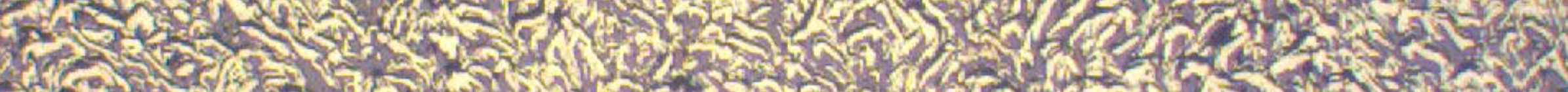

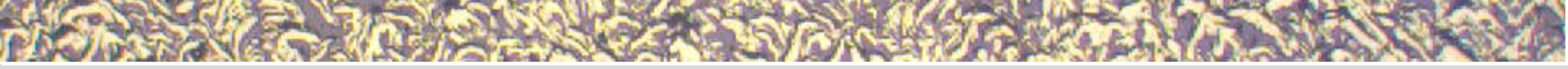

